\title{
THE AESTHETIC DISCOURSE OF DECORATIVE ART (ISLAMIC CIVILIZATION AS A MODEL)
}

\author{
Jolan Hussien ALWAN ${ }^{1}$
}

\section{Istanbul / Türkiye \\ p. $635-655$}

Received: $26 / 11 / 2021$
Accepted: 07/12/2021
Published: 01/01/2022

This article has been scanned I iThenticat No plagiarism detected

\begin{abstract}
:
Islam is a major turning point in the life of the nation in particular and humanity in general, because the impact of the Arab-Islamic civilization on human life as a whole is still visible. Art was a manifestation of the Arab Islamic culture and that it represents a pattern of human civilization patterns. Arab Islamic art is one of the important tributaries that accompanied the life and development of the Arab Muslim man. Islamic religious buildings, such as statues, pictures, and other tools used by the Christian churches in their rituals, as these teachings prevented from imitating nature completely. The abstract of the reality of the Creator. This spiritual identity of art is the prominent feature that has marked the history of Islamic art, in all its diverse fields, from diagnosis to abstraction.

The Arab-Islamic personality crystallized under the Islamic religion, and art and its aesthetics became a source of interest for Muslim philosophers of beauty, including Al-Ghazali, Abuhyan AlTawhidi and Al-Farabi, because Islamic religious thought is far from everything that is analogous in Islamic art so as not to be an emulation of the Creator.

From here, the research problem started with the following question: What distinguished the decorative art from the rest of the Islamic arts through its vast civilization from the other arts? And to what extent does it include the aesthetic dimension within the opinions of Muslim philosophers who are interested in the aesthetics of art?

1-As for the importance of the research, it focused on: the possibility of considering it a source for those interested in studying decorative.

2-The possibility of seeing the aesthetics of decorative art and the artist's orientation to this type of art.
\end{abstract}

Key words: Decorative, Islamic Art, Culture.

http://dx.doi.org/10.47832/2717-8293.15.44

1 iD Dr. , University of Diyala, Iraq, jolanhussien33@gmail.com 


\section{الحطاب الجمالي للفن الزخرفي \\ (الحضارة الإسلامية أنموذجا) \\ جولان حسين علوان 2}

الملخص:

يعد الإسلام نقطة تحول كبيرة في حياة الأمة بصورة خاصة والإنسانية بصورة عامة، ذلك إن التأثير الذي أحدثته الحضارة العربية الإسلامية في الحياة البشرية قاطبة ما زلنا نلمسه ظاهراً. وقد كان الفن مظهراً من مظاهر الثقافة

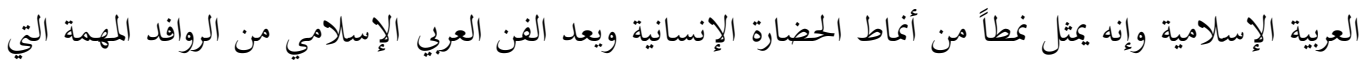

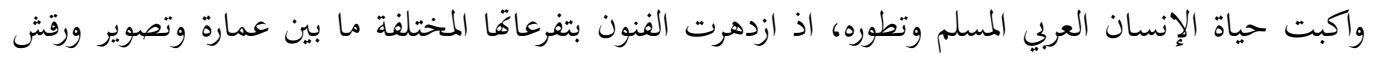
وخط وصناعات زخرفية وزجاجية ويدوية مختلفة، وقد خلت العمائر الدينية الإسلامية من التماثيل والصور وما إليها من الأدوات التي تستخدمها الكنائس المسيحية في طقوسها، كما حالت هذه التعاليم دون تقليد الطبيعة

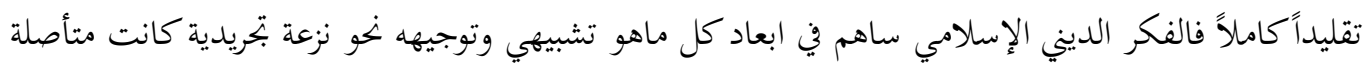

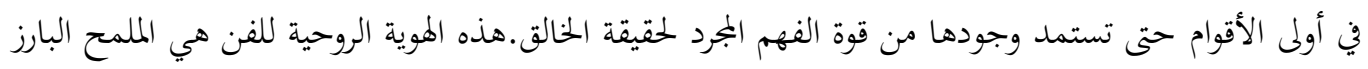

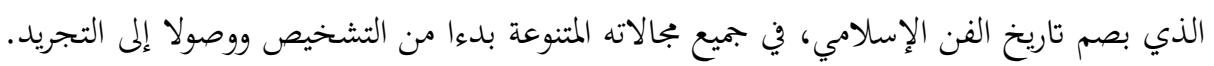
والشخصية العربية الإسلامية تبلورت في ظل الدين الإسلامي واصبح الفن وجمالياته مصدر اهتمام فلاسفة

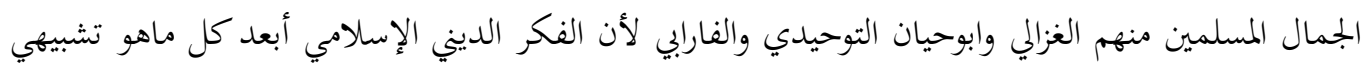
في الفن الإسلامي حتى لايكون مضاهاة للخالق.

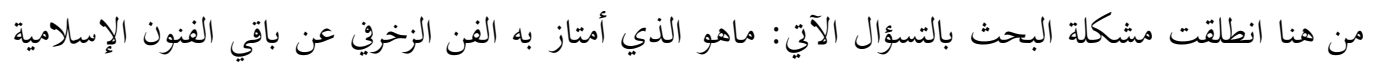

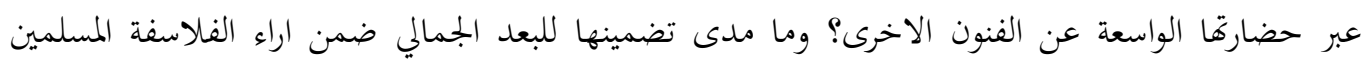

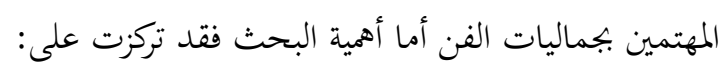
1 - 1 -إمكان اعتباره مصدر للمهتمين بدراسة الفن الإسلامي. 2-إمكانية الإطلاع على جمالية الفن الزخرفي وتوجه الفنان إلى هذا النوع من الفن. الكلمات المفتاحية: الفن الزخريف، الفنون، الحضارة الإسلامية. 


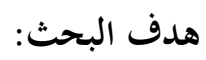

الكشف عن الخطاب الجمالي للفن الزخريف في الحضارة الإسلامية.

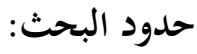

يتحدد البحث الحالي بدراسة الزخارف الفنية الإسلامية بجميع أنواعها.

وقد توصل البحث إلى اهم النتائج التالية:

1-الخطاب الجمالي يقوم على فلسفة الفنان المسلم من حيث الاعتقاد بلا هاية الوجود، فلمسلم يرى الله هو مركز الكون وكل شيء يبدء منه ليعود أليه . 2- 2 الابتعاد عن تمثيل الطبيعة وتقليدها. 3-الاهتمام بالزخارف المتوالدة والمتناظرة التي تتمركز حول عنصر لتدور وتعود إلى نفس التكوين.

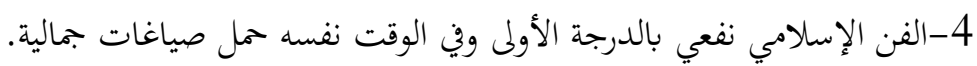

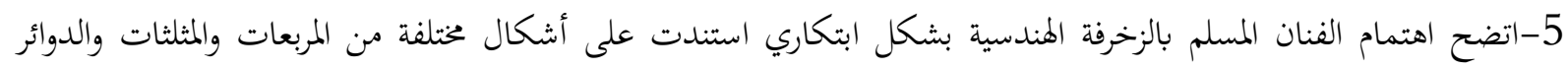
المتماسة والأشكال المتقاطعة بصيغة جمالية خالصة. 6-العناصر النباتية مصدرها فروع النبات واوراقه وازهاره ولكن بأسلوب محور .

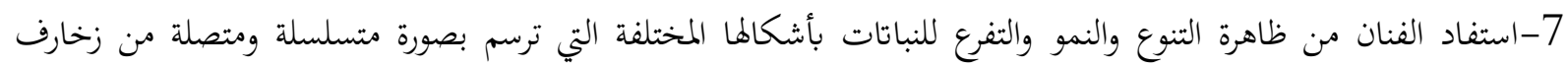

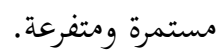
8 -استخدم الفنان المسلم الحطط العربي في الزخرفة والتزيين وفي بعض الاحيان أدخلوا عناصر نباتية في انتهاء الحرف.

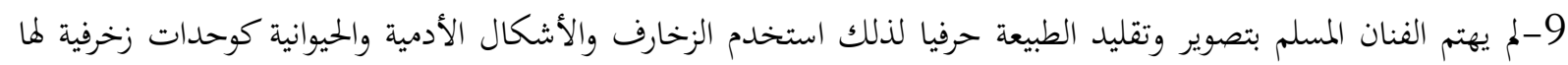
قيمتها الجمالية. 10-اشتهر الفن والتراث الإسلامي إضافة إلى الزخارف بفن الكتابة والتصوير وفن العمارة وفن الخزف وغيرها من الفنون التي جملت الطابع الجمالي. 


\section{الفصل الأول}

مشكلة البحث

ارتبط مفهوم الفن الإسلامي بما جاءت به التعاليم الدينية، فالفنان المسلم وظف نوع من الخطاب الشكلي للتعبير عن

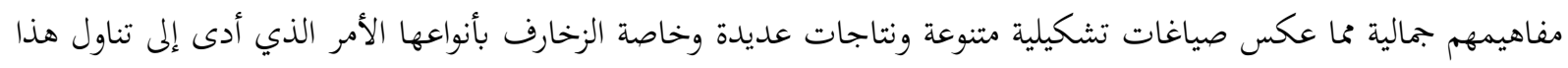

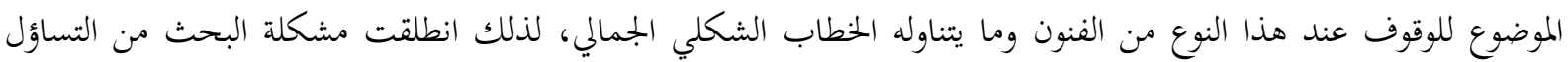

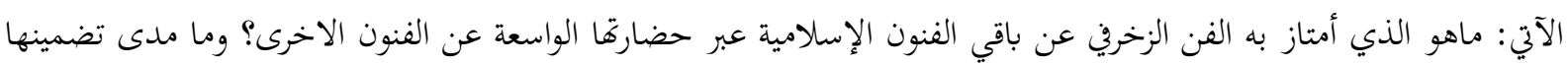
للبعد الجمالي ضمن اراء الفلاسفة المسلمين المهتمين بجماليات الفن.

أهمية البحث تتجلى أهمية البحث في: - - إمكان اعتباره مصدر للمهتمين بدراسة الفن الإسلامي.

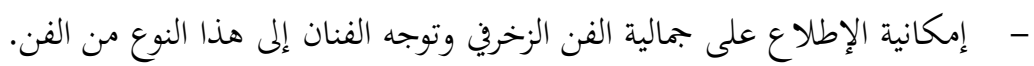

هدف البحث يهدف البحث الحالي إلى الكشف عن: الخطاب الجمالي للفن الزخرفي في الحضارة الإسلامية .

حدود البحث هناك الكثير من الفنون الإسلامية المختلفة والمتنوعة، لذلك تحدد البحث الحالي بدراسة الخطاب الجمالي للزخرفة بأنواعها

المختلفة.

تحديد مصطلحات

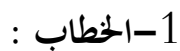

الخطاب عند (أرسطو) هو"الكلام المقنع. وهي نوع من القياس. والأدلة عنده قسمان، الأول خارج عن الفن

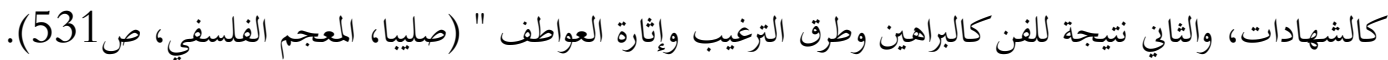
الخطاب عند (الفارابي) هو " كالجدل - تشتمل على البرهان المشوب. إلا أن الخطابة تعلم البرهان على الذي كذبه مساو لحقه،

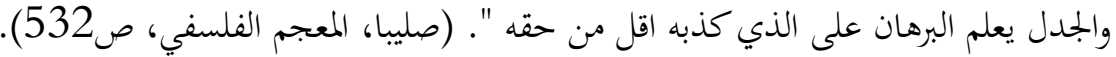
الخطاب عند (لالاند) "عملية فكرية بتري من خلال سلسلة عمليات أولية جزئية ومتتابعة. بنحو خاص، تعبير عن الفكر وتطوير

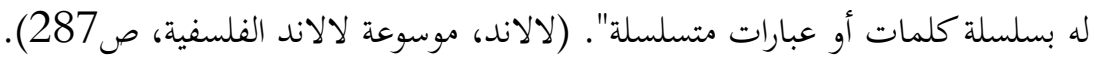
2 -الجمال:

جاء تعريف الجمال على أَنه"التناسب التام الممتع" (حسان، مقدمة في علم الجمال، ص16)، كما تم تعريفه على انه:

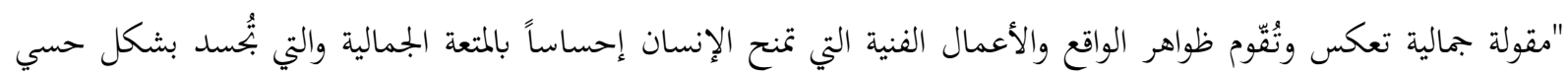


موضوعي حرية القوى الإبداعية والمعرفية وتمامها، وقدرات الإنسان في كل مجالات الحياة الاجتماعية، جوانب العمل والجوانب

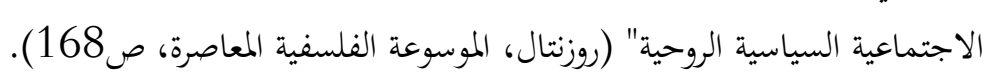
ويُعرف (كانت) الجمال على أنه " الإدراك الذي يصاحبه إثباع الحاجة الجمالية عن طريق الشعور بالمتعة، الخالية من أي

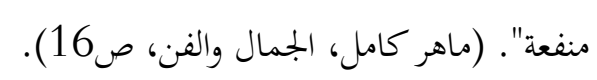
والجمال عند (سانتيانا) "يوجد في الإدراك ولا وجود له في غير ذلك. والجمال الذي لا يدرك هو لذة لا تُّس ومن تم فهو

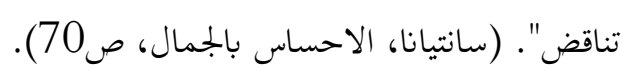
وقد جاء الجمال بتعريف (هربرت ريد) الذي يستند على أساس مادي حسي مفاده" إن الجمال وحدة للعلاقات الشكلية

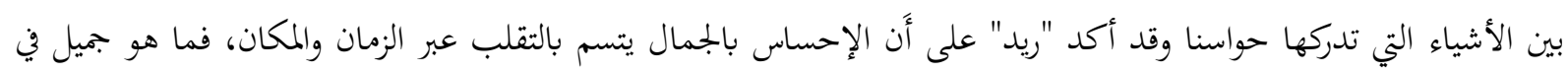

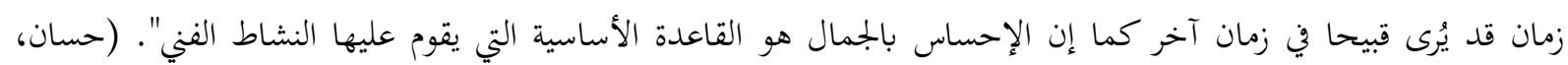

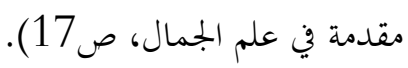




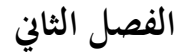

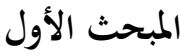

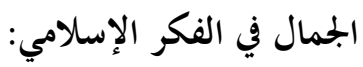

الفلسفة الجمالية الإسلامية انطلقت من روح الوحدانية وبلغت ارقى مراتبها وأكملها وقد تعددت الرؤى والأفكار الفلسفية، إذ نجد أن العرب المسلمين كانت لهم محاولات في تحديد مفهوم الجمال. ان الفلاسفة المسلمين تميزوا بنظرقم الفاحصة مرته

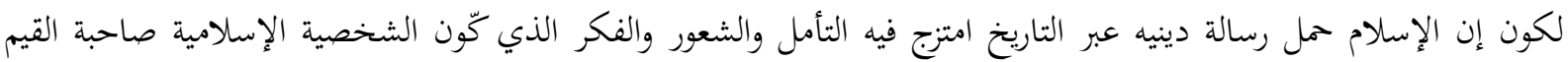

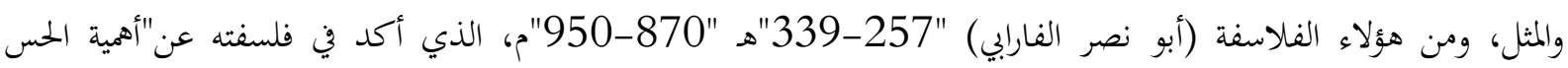
والمسوس فقد عد الفن صفة حسية أساسها التجريب، يتصف بالتصوف الرومانسي الرافض للماديات المبتذلة مصفيا للأرواح

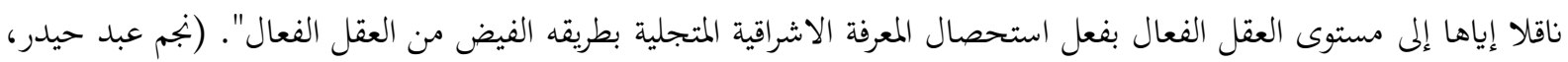

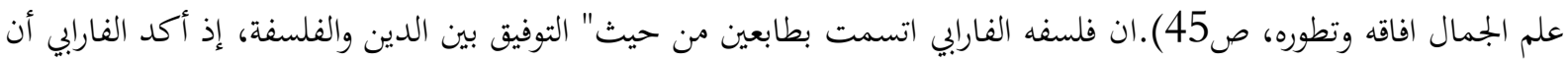

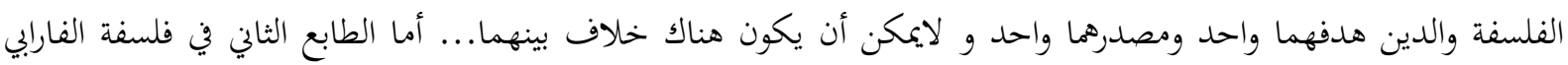
فهو التوفيق بين رأي أفلاطون وأرسطو ورفض أي اعتبار لخلافهما وهذا ماجاء في كتابه" الجمع بين رأي الحكمين" (نجم عبد واحد حيدر، علم الجمال افاقه وتطوره، صين راي الاطون ورسطو ورفض ال423).

فيعتقد الفارابي بان الخلاف بين أرسطو وأفلاطون كان خلافا بالظاهر وليس بالجوهر فمزج بنزعة رومانسية تحمل في طياتا

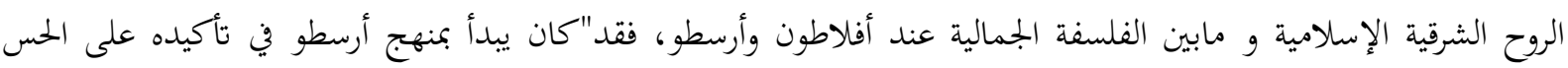

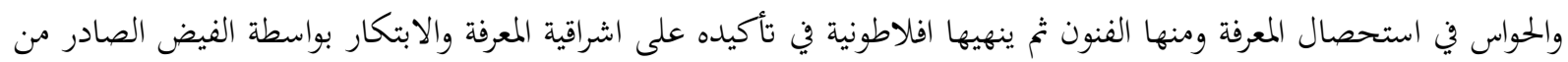
العقل الفعال واهب الصور الأبدية، فقد امتزج النظام الحسي ومعطياته وأهميته بالنظام المثالي الاشراقي الفيضي بواسطة التجرئه

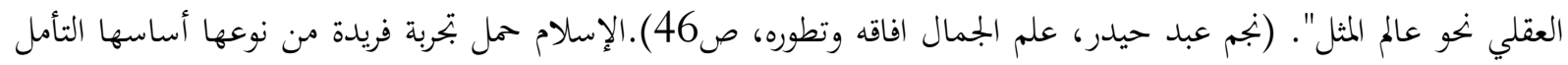

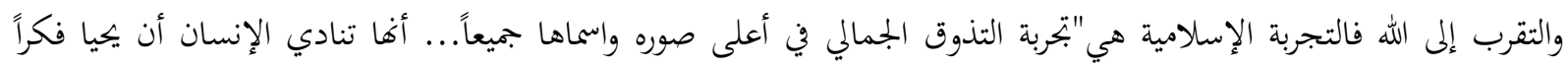

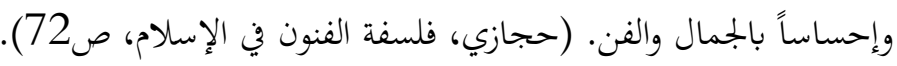

وهذا يؤكد الرؤية المثالية لابي نصر الفارابي على الرغم من تحديده درجات العقل وفعالياته وصولاً إلى اعلى المراتب وهي (الله

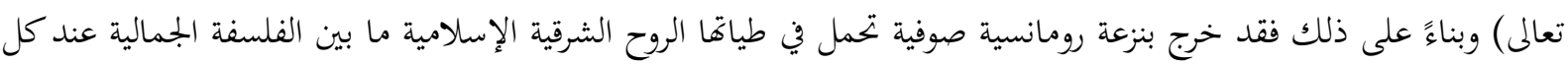

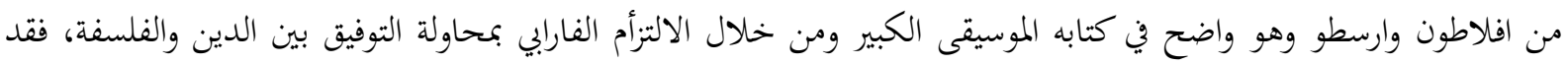

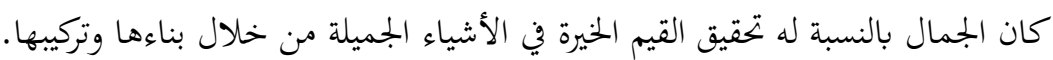
ومن خلال ما تقدم يتضح ان الفارابي قد حدد أو اشترط القيم الخيرة في معيار جماله وان صوفي النزعة، افلاطوني المثال وارسطو واقعي وهو ما عمل عليه، اذ حاول التوفيق بين الفلسفة الإسلامية والاغريقية لدى افلاطون وارسطو. أما الفيلسوف (ابن سينا) "370-428"هـ "980-1073" م.، فقد اتسمت فلسفته بأغا "عقلية في أصولها فهو كالفارابي يؤمن بالعقل الفعال مصدر للعلم والمعرفة، كما يؤمن به أيضا مصدراً للإلهام الروحي وتتسم فلسفته بأها صوفية في ألفاظها وتعابيرها وتوفيقية في غاياتا وأهدافها فلقد كان الطابع العام لفلسفة ابن سينا كما هو الحال عند الفهاب الفارابي التوفيق بين

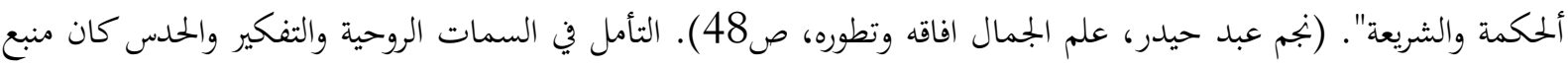

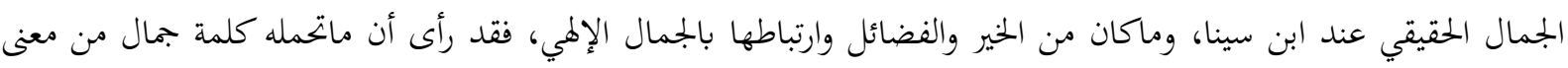

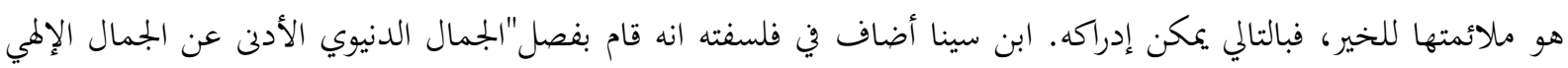

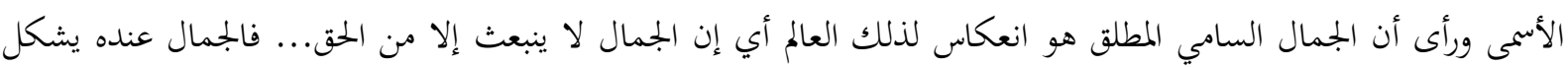


مفهوم متعدد الإطراف يدخل العقل في مجال فكري خالص فلا يوجد أي نوع جمال أو بهاء أكثر سمو من الجمال العقلي الخير

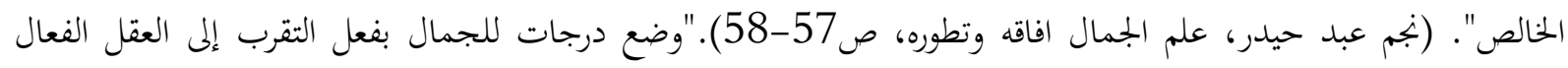
واهب الصور وواهب الكليات وبالنتيجة واهب الجمال، فالجمال الحقيقي هو الجمال الإلهي، الجمال المقترب من الجمال السماء

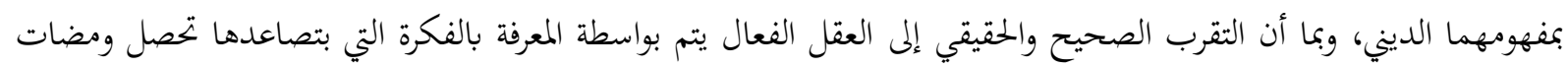

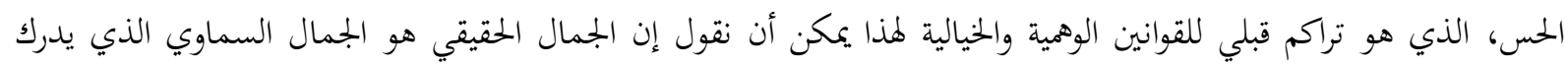

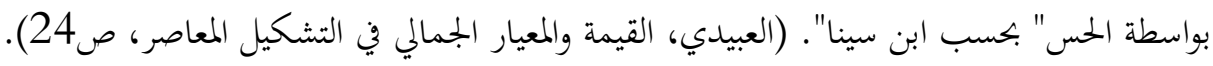

واشتملت المعرفة عند ابن سينا على ثلاثة مستويات:

$$
\begin{aligned}
& \text { 1- 1 "معرفه بالفطرة..." العقل الابتدائي العملي." } \\
& \text { 2- معرفه بالفكرة.... " العقل المستفاد." } \\
& \text { 3-معرفه الحدس..." العقل المبدع. المبتكر. العقل القدسي. الروح القدسية" بالفخرة. }
\end{aligned}
$$

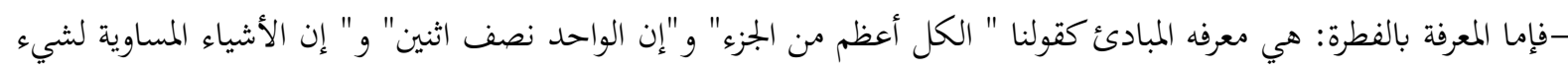

$$
\text { واحد متساوية." }
$$

- بما أن المعرفة بالفكرة مكتسبه وتكون بإدراك المجردات المعقدة والكليات العامة والانتعاش بها، والمرء يحتاج إلى مجهود أكبر من

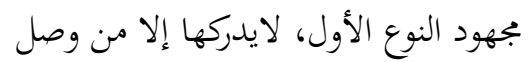

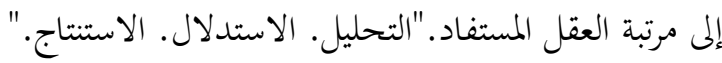

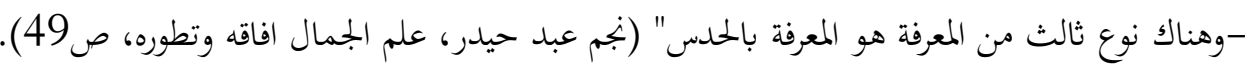

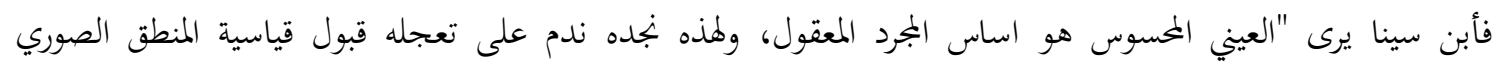

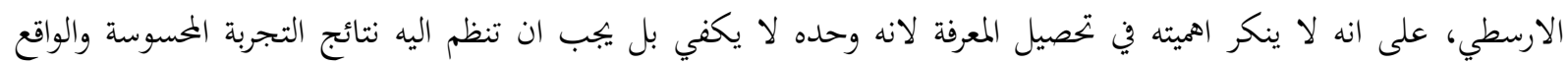

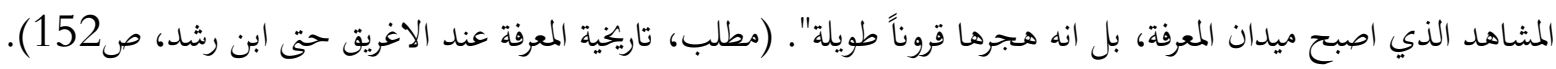
وعند انتقالنا إلى الموقف الجمالي عند (أبو حامد الغزالي)"1058-1111"نجده يقول "واعلم أَن كل جمال محبوب عند مدرك ذلك الجمال، والله تعالى جميل يحب الجمال وأَن كان الجمال بالحلال والعظمة وعلو الرتبة وحسن الصفات والأخلاق وأرادة

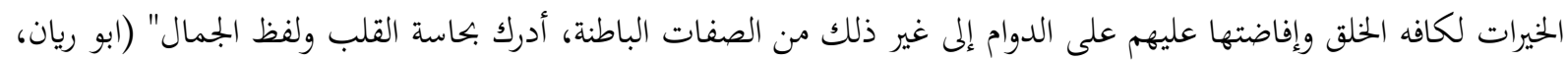

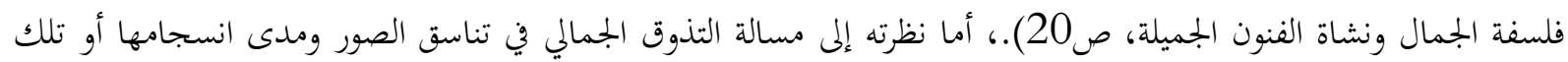
التي لها علاقة بالصفات ألباطنة وكيفية إدراكها، أو تلك التي تدرك بالعقل، نجده قد أشار إلى ثلاثة ظواهر مهمة وهي "حسية، وجدانية، عقلية"، موقف الغزالي الجمالي ارتبط أيضا بالجمالية الإلهية، إن كانت حسية وجدانية أو عقلية.

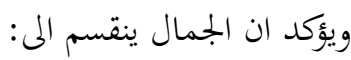

1 1 -"جمال الصورة الواضحة المدركة بعين الراس وهو جمال حسي.

2-جمال الصورة الباطنة المدركة بعين القلب ونور البصيرة وهو جمال وجداني" (الغزالي، احياء علوم الدين، ص306). إما الفيلسوف العربي (ابن رشد)"1126-1194" نجد أَنه قد عارض الغزالي"الذي دافع عن أسس "الاحتمالية المثالية"

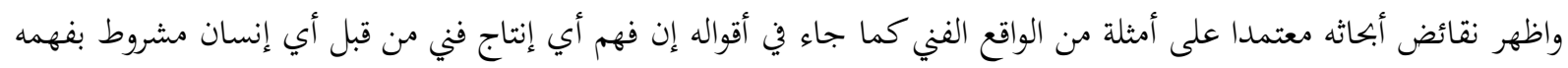

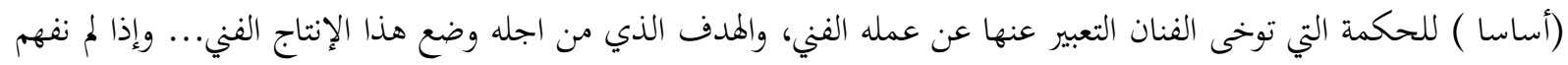

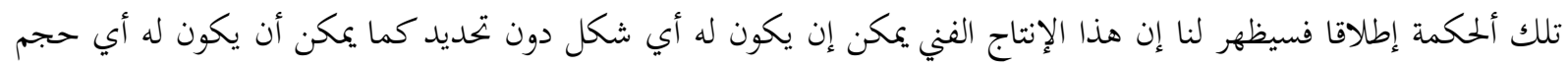

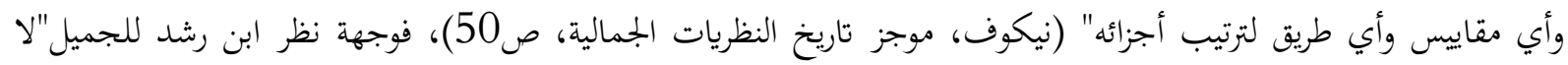


ينبغي أن تفهم كقيمة أو كطبيعة كونه كذلك وإنما يتعين أن يستدل عليه من تناول منهاجي تحليلي لواقع مدرك ينظر إليه على انه

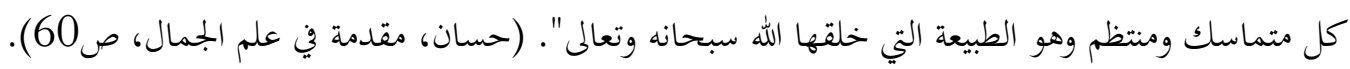

وهناك الفيلسوف العربي الإسلامي الأخر (ابو حيان التوحيدي) الذي يتساءل قائلاً: "ما سبب استحسان الصورة الحسنة؟

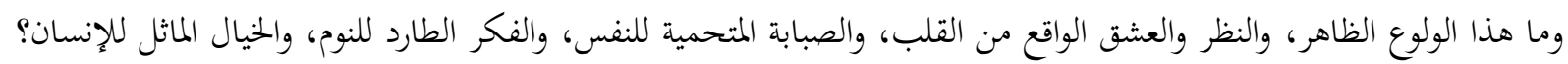

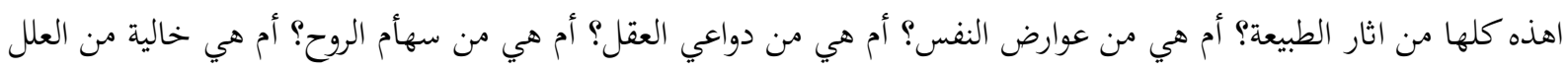

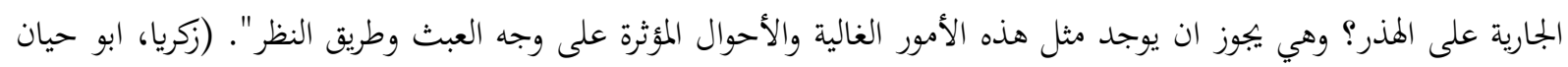
التوحيدي، ص273)

"لقد وضع التوحيدي شروطاً للتذوق الجمالي اولها اعتدال مزاج المتذوق والثاني هو تناسب اعضاء الشيء المتذوق في

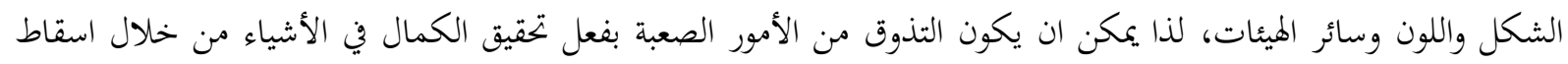

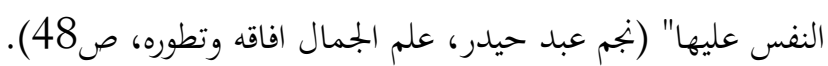

وفي هذا يذكرنا التوحيدي باشتراطات التناسب بين الاجزاء للعمل الفني لدى ارسطو وانسجأماته بين عناصره المتعددة

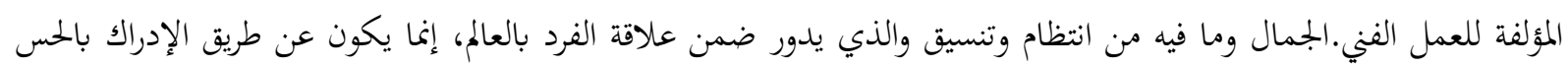

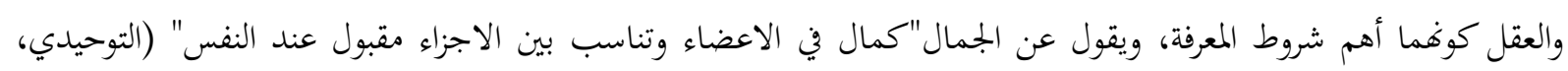

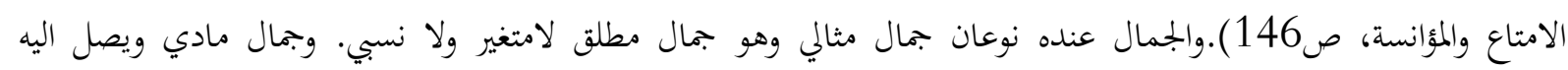
بالحواس وخاضع للتغيير، فالتوحيدي يربط الجميل بما هو نافع وخير. اما (ابن قيم الجوزية) فقد قسم الجمال المي: - الم 1 2-جمال باطن وهو يرى بان الجمال الباطن هو المحبوب لذاته وهو جمال العلم والعقل والجود والعفة والشجاعة وهو محل نظر الله

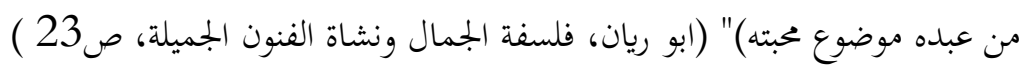
اما الفيلسوف ابن حزم الاندلسي فقد ذكر في كتابه (طوق الحمامة) عن الجمال"ان النفس الحسنة تولع بكل شيئ حسن،

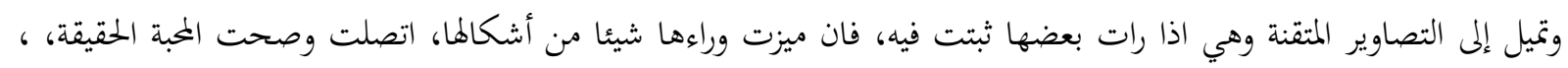

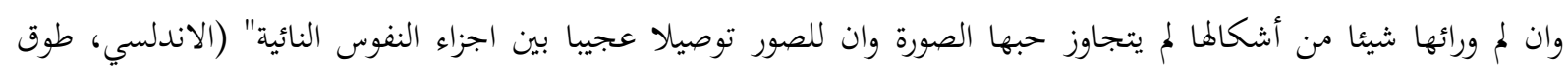
الحمامة، ص22).

وكان من أهم المفاهيم التي لعبت دورا ذات أهميه في نظريات الفلاسفة الجمالية هو" مفهوم التناسق " الهارمونيه" إن المفهوم

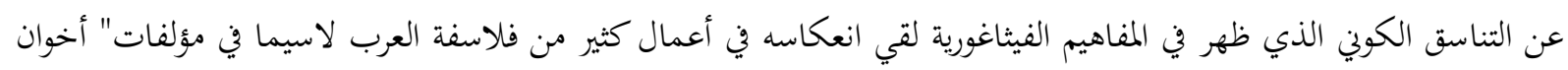

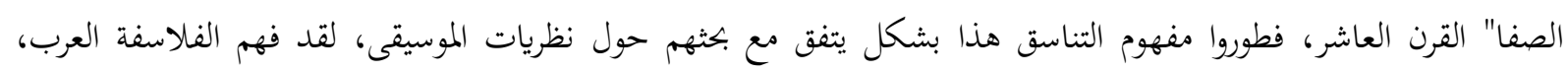

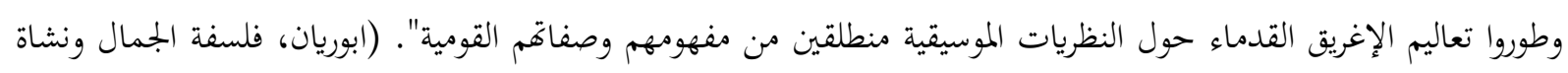

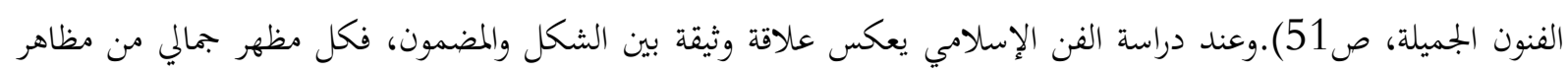
الفن الإسلامي يعكس مضمون فلسفي حامل لخطاب جمالي. 
للفن الإسلامي مكانة مهمة لكونه قد حمل خطاب لصور منتزعة من واقع الحياة الطبيعية أو انعكاسا لاشعوريا لوجدان وواقع الفنان ذاته، حيث كانت العلاقة بينه وبين الإسلام بوصفه فلسفة للحياة وعقيدة للإنسان المسلم ونظاما للمجتمع الجلديد

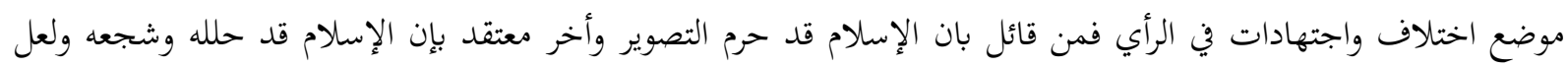

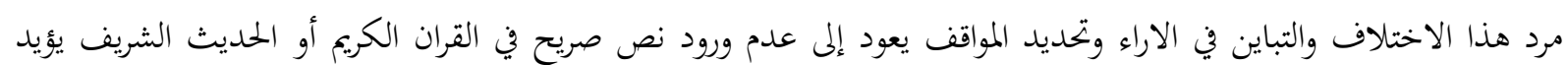
التحريم أو يؤكد التحليل.

أهم سمات الفن الإسلامي هي الفلسفة التي يقوم عليها من حيث الاعتقاد، فلمسلم يرى الله بقوته وعظمته ورحمته هو مركز

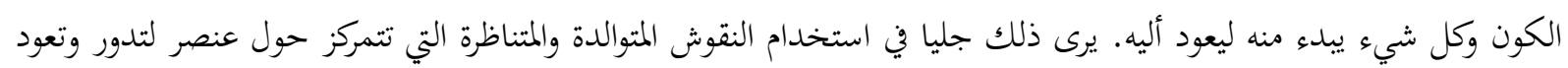

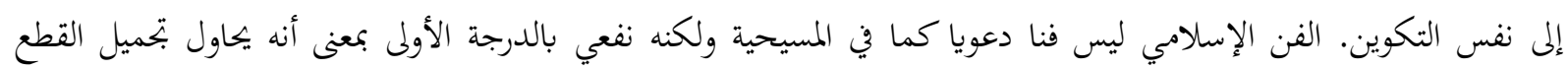

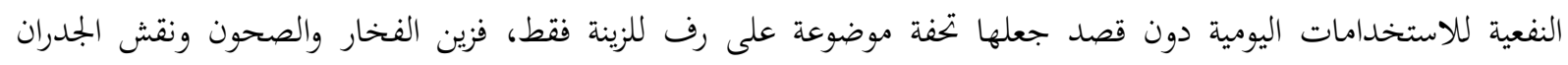

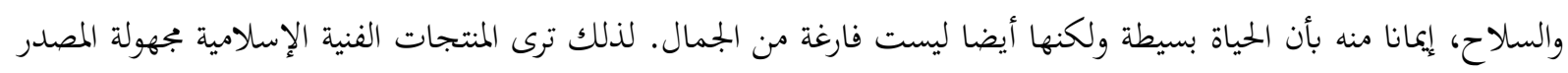
أو الصانع، لأن من يصنعها لم يقصد منها تقديم نفسه كفنان مستقل ولكنه كان يحرص على تقديم شيء جميل ينتفع به. لقد تطرق الفن الإسلامي إلى مجالات عدة، كالفخار والبناء (المساجد والقصور) والمعادن (السلاح والأواني والحلي)، و النسيج (السجاد والأقمشة).

كما عرف الفن الإسلامي التعامل مع بعض الخامات بابتكارية جميلة كالورق والجلود والخشب ووظفها بحرفية عالية. فتجد النجارة في الفن الإسلامي قد أسست لعلم جديد وإبداعي في استخدام الخشب وتطويعه بطرق غير مسبوقة كالارابيسك

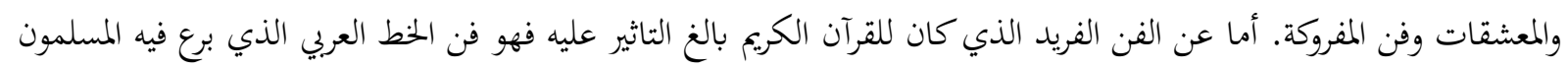

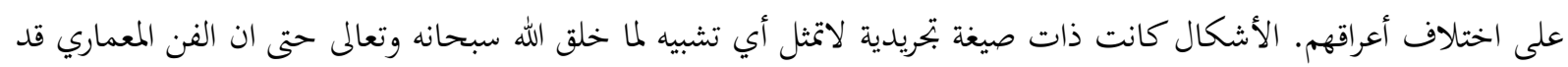

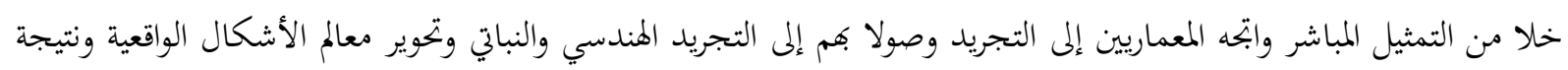

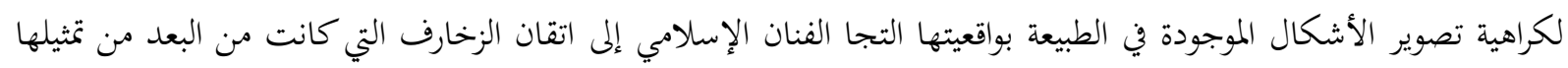
وبتحسيمها للطبيعة.انظر شكل 1، (2).

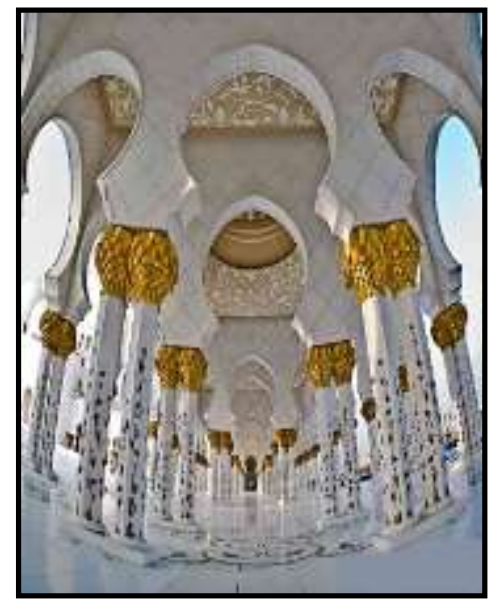

شكل (2) - )

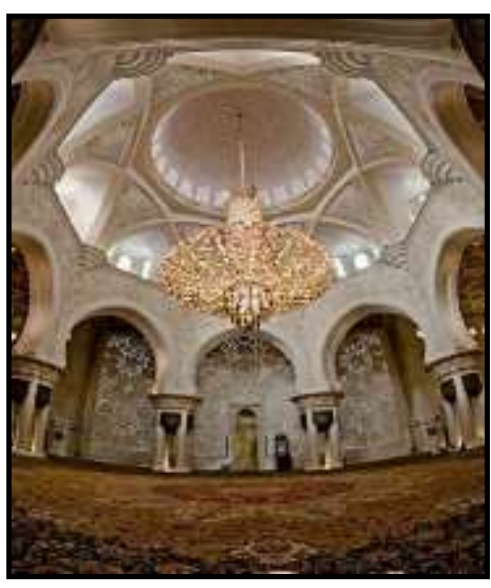

شكل (1) - ) 
يعد الإسلام نقطة تحول كبيرة في حياة الأمة بصورة خاصة والإنسانية بصورة عامة، ذلك ان التأثير الذي أحدثثه الحضارة العربية الإسلامية في الحياة البشرية قاطبة ما زلنا نلمسه ظاهراً."

ويعد الفن العربي الإسلامي من الروافد المهمة التي واكبت حياة الإنسان العربي المسلم وتطوره، اذ ازدهرت الفنون بتفرعاهما

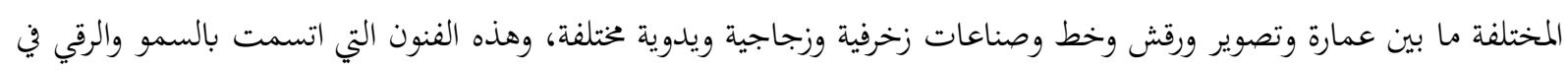

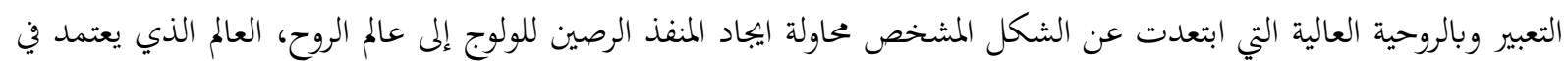

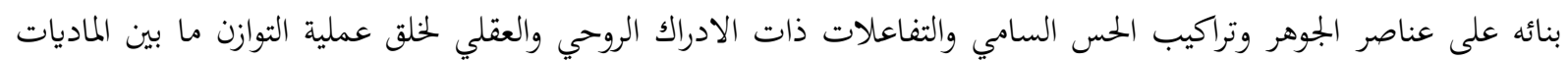

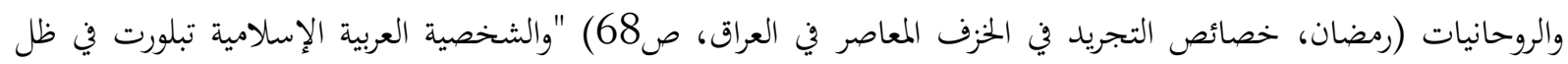
الدين الإسلامي واصبحت ذات كيان ووحدة متكاملة، وظهر ذلك جليا في الفنون التشكيلية والعمارة الإسلامية (الالوسي،

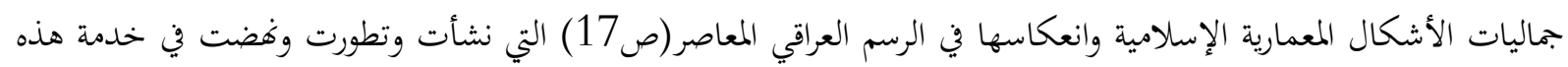

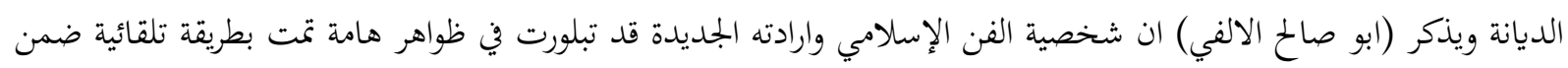
اطار الفلسفة الشرقية العامة واوجزها بما يأتي: 1 - كراهية تمثيل الكائنات الحية.

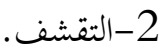

3-الاهتمام بزخرفة السطوح وشغل الفراغ." (الالفي، التذوق وتاريخ الفن، ص26-27). وبذلك لم يتجه الفنان المسلم إلى النحت في المدة الإسلامية وذلك طبقاً لتعاليم الإسلام فقد "خلت العمائر الدينية

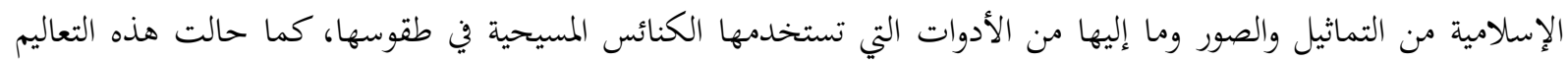

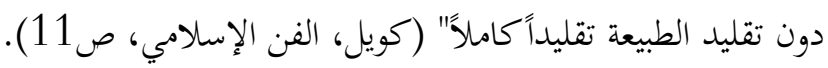
فالفكر الديني الإسلامي ساهم في ابعاد كل ماهو تشبيهي في الفن الإسلامي وتوجيهه نخو نزعة تجريدية كانت متأصلة في

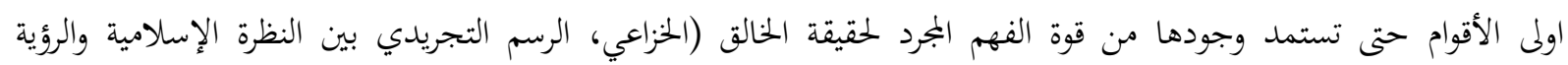

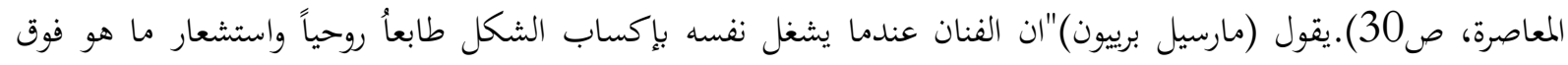

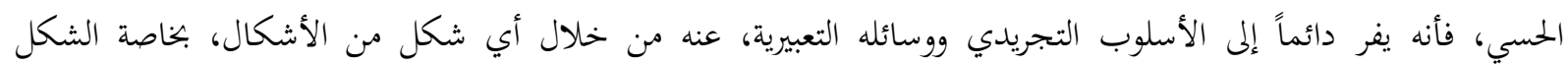

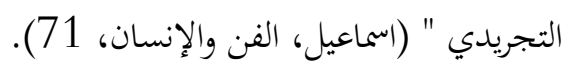
فنرى عدم رغبة الفنان المسلم وميله إلى النحت لأن الإسلام عندما جاء اعلن الحرب على الاصنام والوثنية وقد جاء ذلك

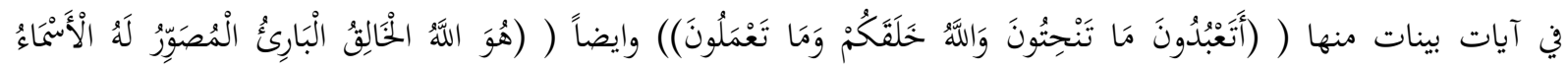

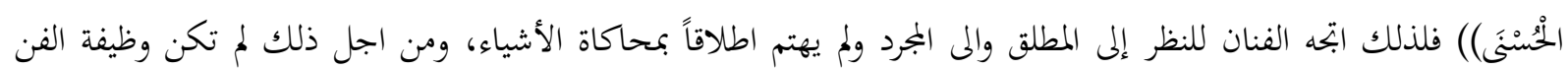

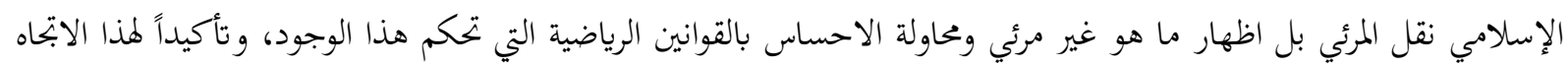

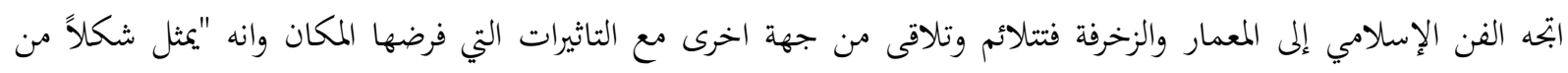

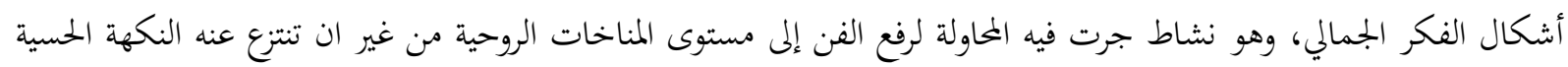

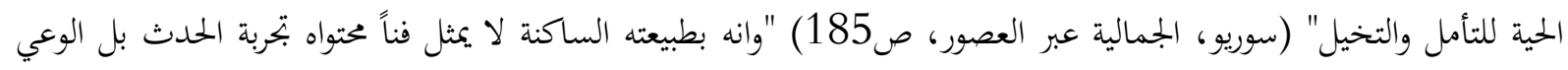

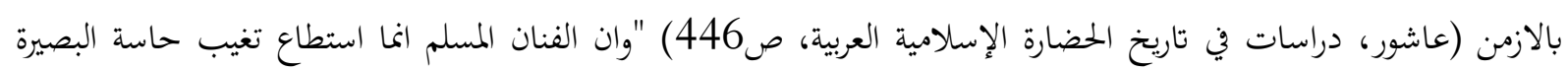

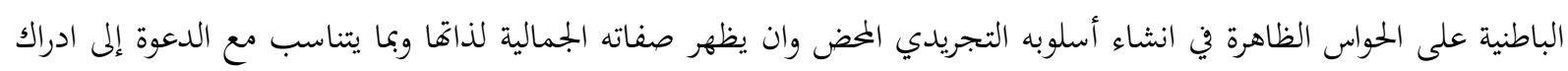

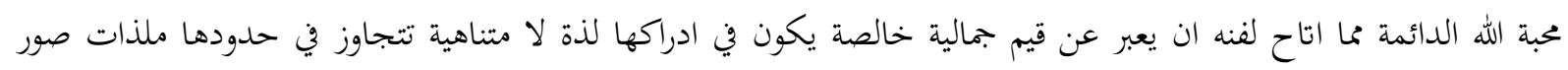

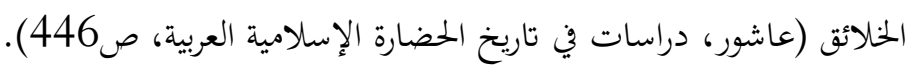


الفنان المسلم اوجد للطبيعة نظاما خاصاً بها وفرض عليها عالماً تشكيلياً نقلها من المدرك الحسي والظواهر الموضوعية إلى

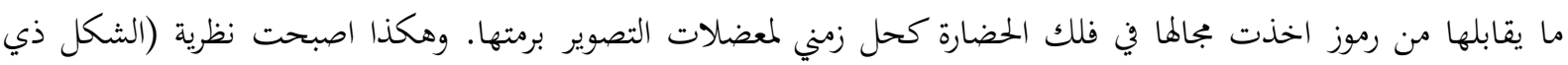

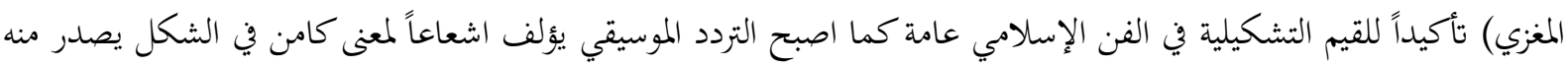
وينبيء عن صفاته الصورية. وكنتيجة لهذه الحالة، انتهى كل عصر إلى اختيار ما يناسبه من أشكال الفن، لأن تاثير التركمات التهات

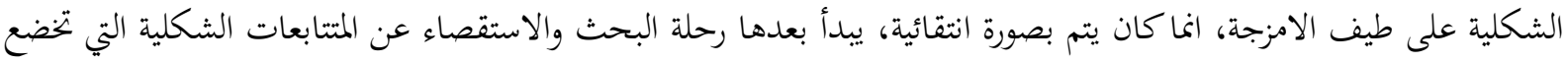

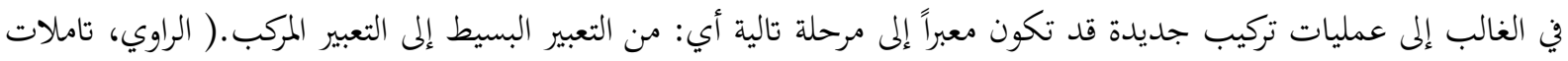
في الفن الإسلامي، ص6 ك-7)

إن الوسائل التصويرية التي هي بطبيعتها وجوهرها قد أعدت لوصف الأشياء وتقريبها إلى الحس اضحت وهي ذات قيمة مجردة فصلت عن موضوعها الذاتي ( ترمي إلى التعبير عن الافكار ) أو الترجمة عن المشاعر بشكل متسام يقرب من مهمة المطلق

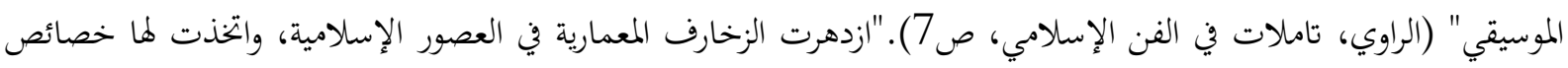

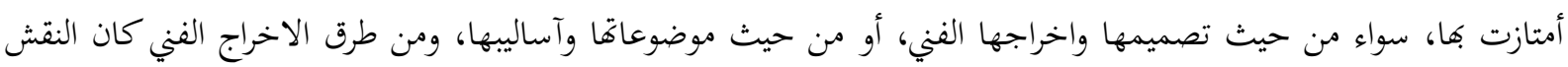

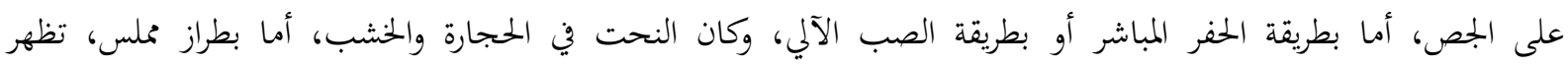

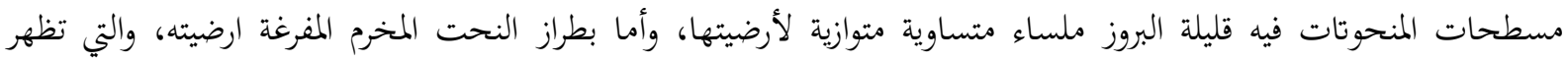
الزخارف عليها ناصعة واضحة المعالم، والارضية غائرة قاتمة، وانتشر استخدام الفسيفساء والقرميد والحجارة المختلفة الالوان".

$$
\text { (فكري، محيط الفنون، صنارف 188). }
$$

كان للفن الإسلامي هدفاً مختلفاً عن أهداف الفنون التي سبقته فقد البحه نحو التحوير والتجريد والتهذيب للطبيعة قد بحاوز

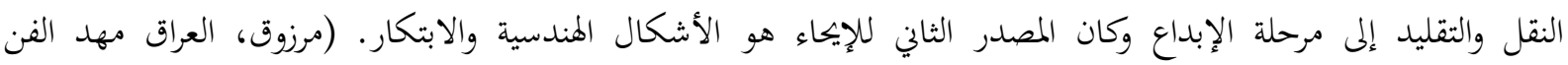

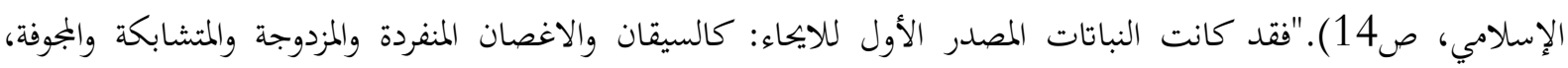

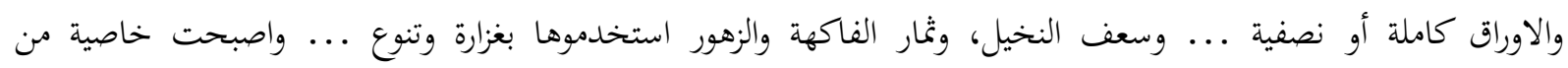

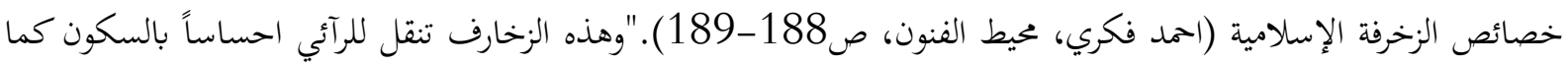

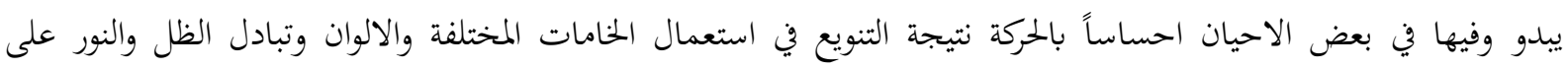

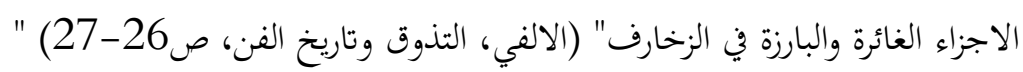

وكانت الكتابة العربية هي المصدر الثالث للايحاء الزخريف المعماري (شكل 37) واما من حيث الآساليب أو طرق التعبير

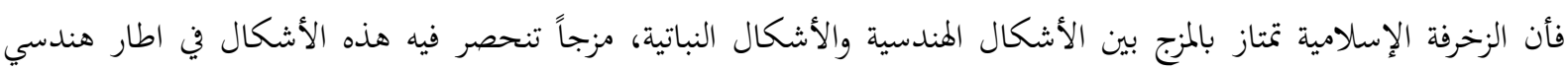

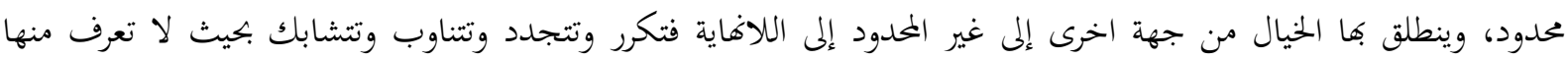

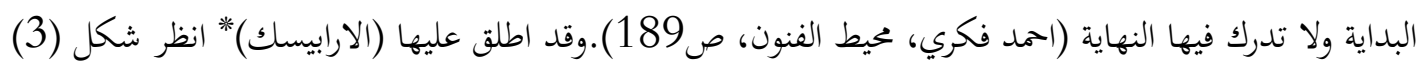

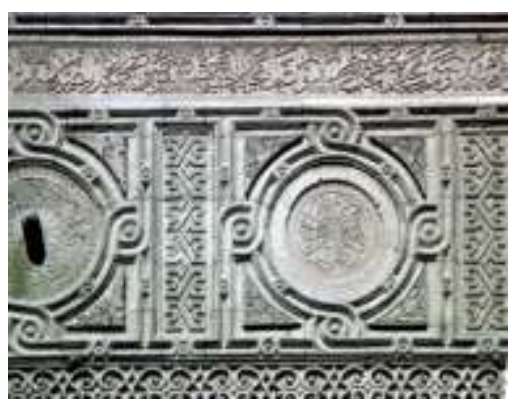

شكل (3) 
إن ابتحاه الفنان المسلم نحو الرقش والزخرفة محاولة نهو الاختزال واللاتشخيص فهو دائماً يبحث عن الروحي والقيم الظاهرة

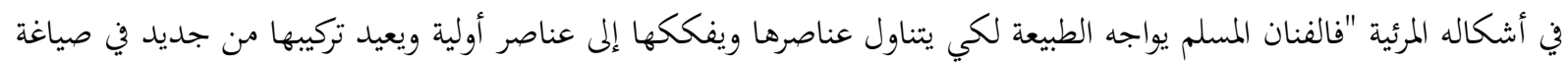

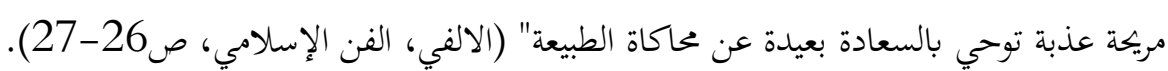

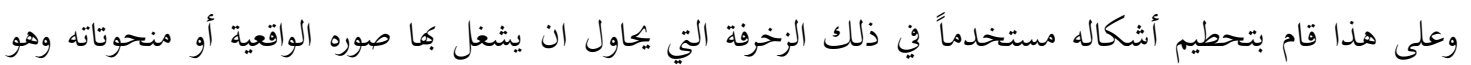

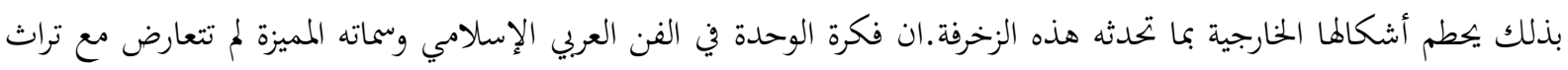

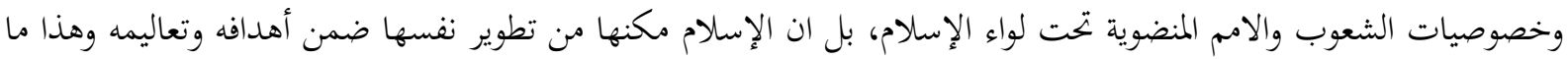

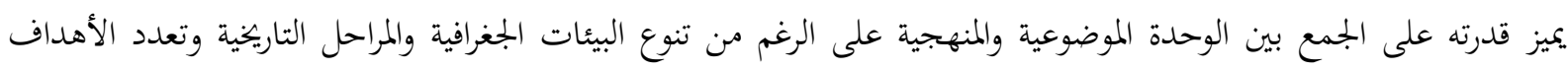

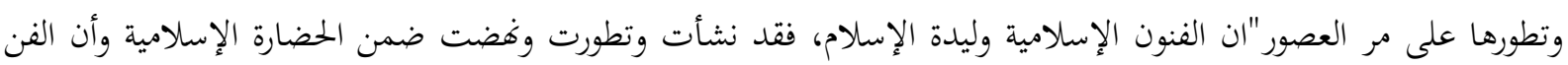

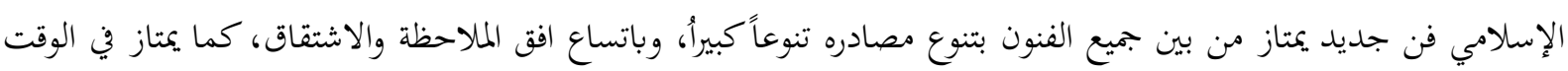

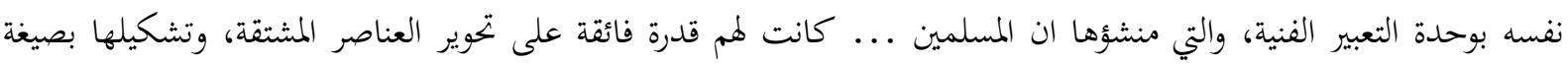

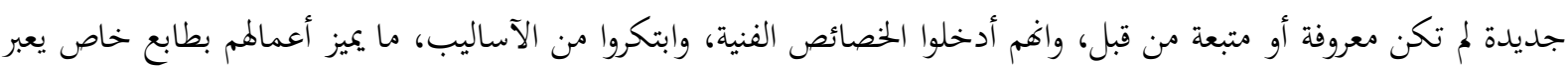

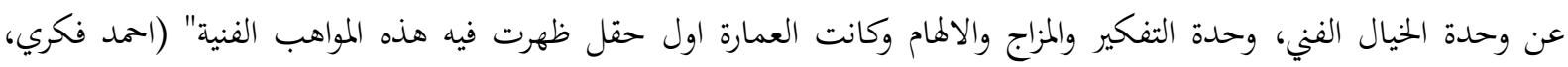

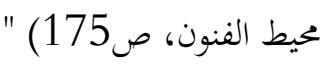
ولذلك انبثتت من الموروث الإسلامي الأشكال المعمارية التي يرجع نشوها إلى السيادة المطلقة للتعاليم القرآنية والشريعة

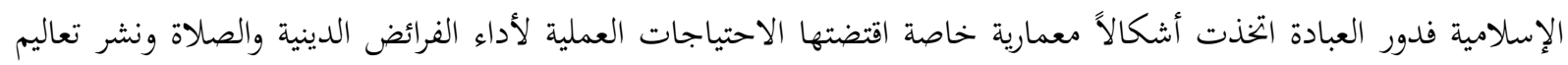

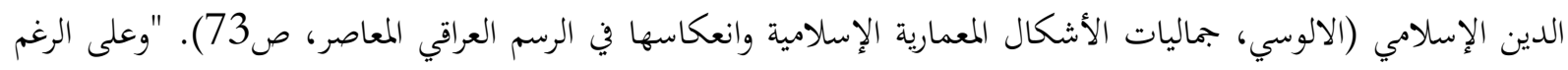

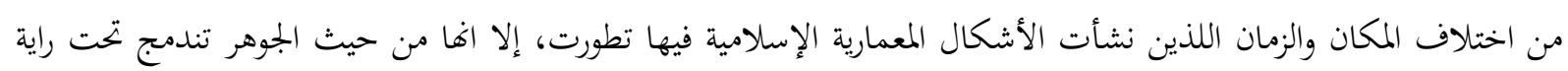

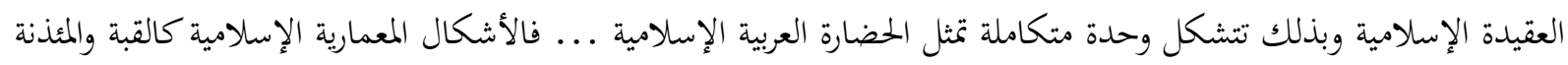
والعقد والحراب والزخرفة وغيرها ... هي اللبنات التي بنت عليها العمارة الإسلامية مجدها وعظمتها ل... وان الفن المعماري هو الإسية

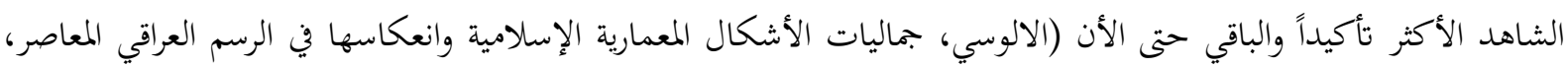

وبالنسبة لهذه التكوينات والأشكال المعمارية فقد شكلت كل واحدة منها عنصراً مهماً ذا قيمة فنية ووظيفة جمالية في آن

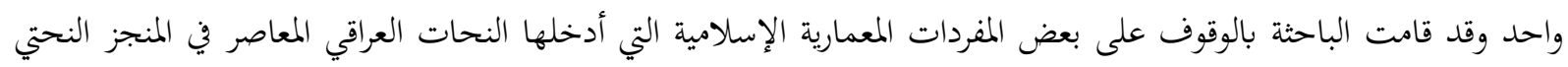

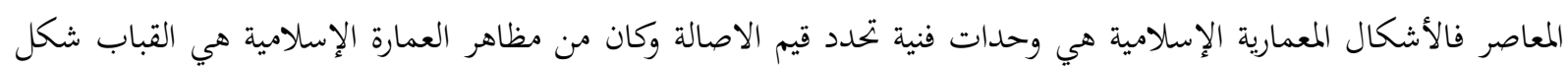

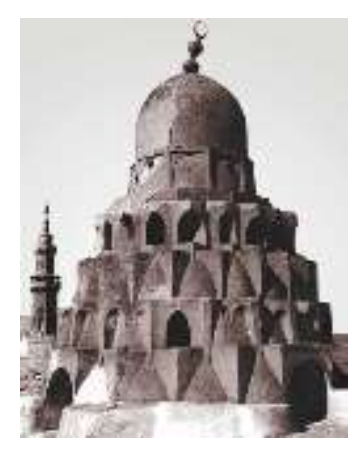

(4) شكل (4)

وقد استخدمت في العالم الإسلامي في الجوامع والاضرحة وهي "من الأشكال المعمارية التي عرفها الفن العربي الإسلامي

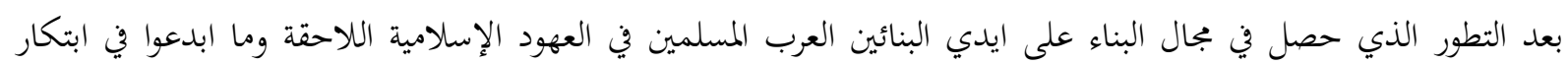


وإضافة وحدات زخرفية هندسية ونباتة وكتابية، مما اضفى عليها سمة جمالية خاصة وجعلها في مقدمة الأشكال المعمارية"

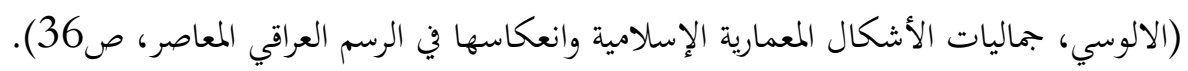

وقد كانت القباب تغطي بالواح من البلاط المزجج، واستخدمت المقرنصات في داخلها على عنق القبة من الخارج وتضيف

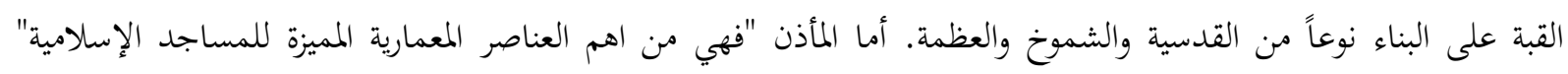

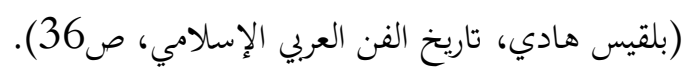

وقد تنوع أشكالها واحجامها من مكعبة واسطوانية وحلزونية وتعددت طوابقها وارتفعت اعناقها وامتشقت قوائمها.

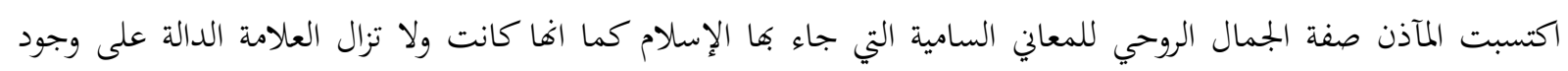

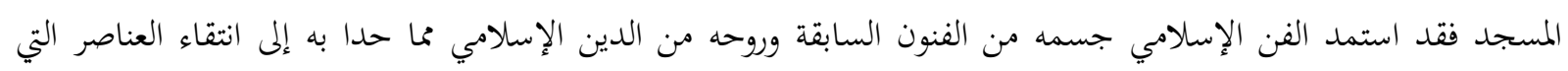

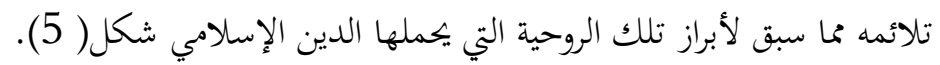

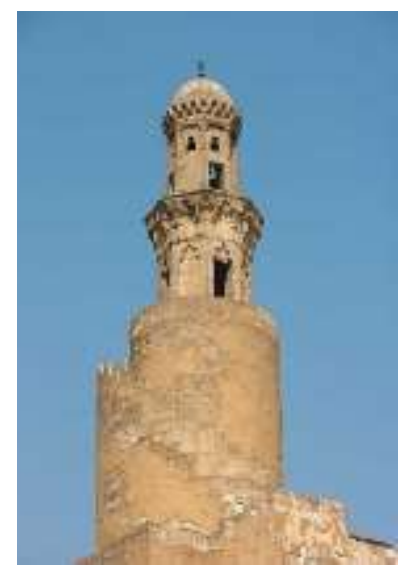

شكل (5)

لأن هناك نغمة اساسية وايقاعاً مشتركاً يتكرر بالحاح في جميع نواحي الوجود الطبيعي والحياة البشرية في الماضي والحاضر"

$$
\text { (الالفي، الفن الإسلامي، صوب). }
$$

وكان المحراب ايضاً ابتكاراً معمارياً وقد وضع في جدار القبلة لتعيين ابتاهها وفكرته كانت عند المسلمين منذ السنة الثانية

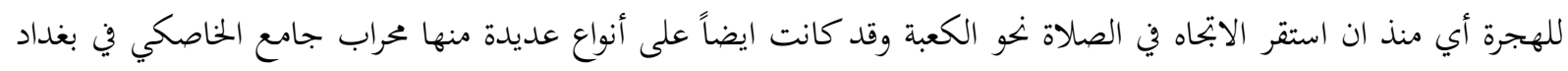
شكل (6)، وتطالعنا الأشكال المعمارية الاخرى وهي العقود والتي كان من ضمنها العقد المدبب شكاه الهل 7.

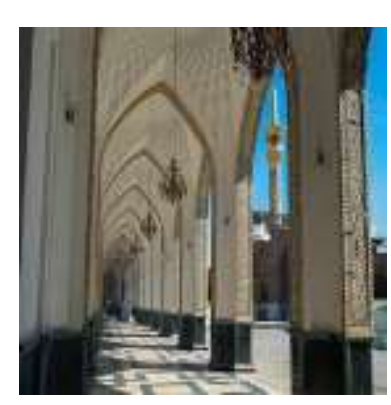

شكل (7)

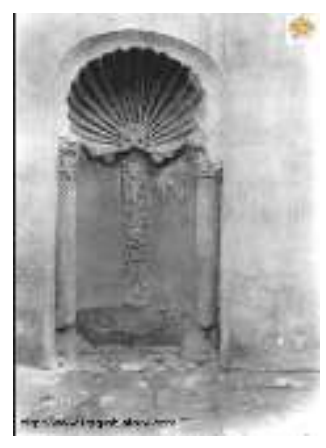

شكل (6) 


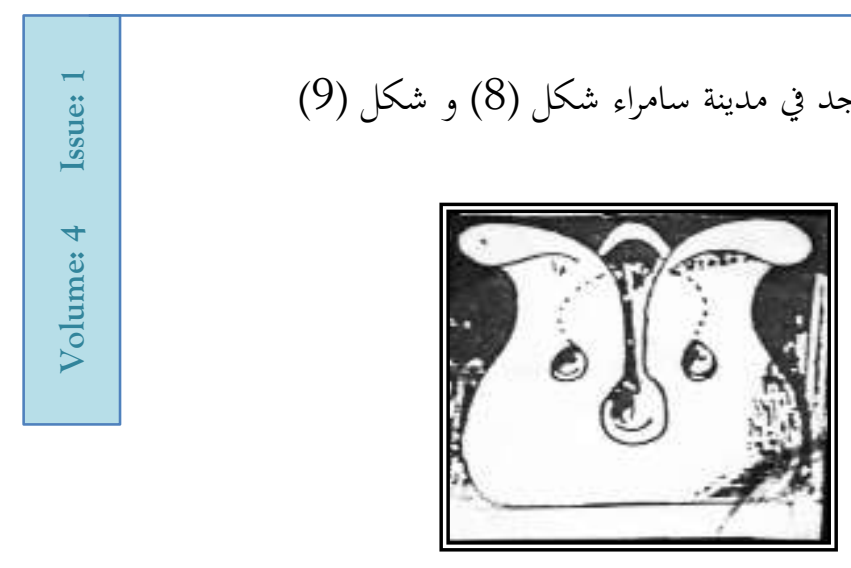

شكل(9)

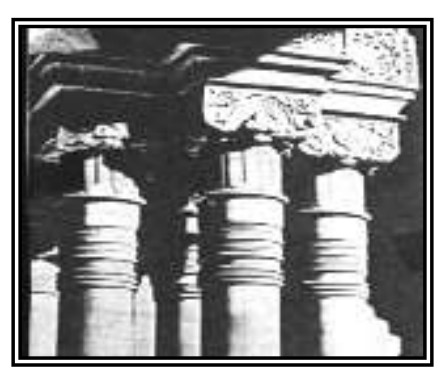

شكل (8)

وخلاصة ما تقدم هو انه نتيجة لأبتعاد الفنان المسلم عن المحاكاة الطبيعة فقد ابحه نخو الزخرفة بأشكالها النباتية والهندسية

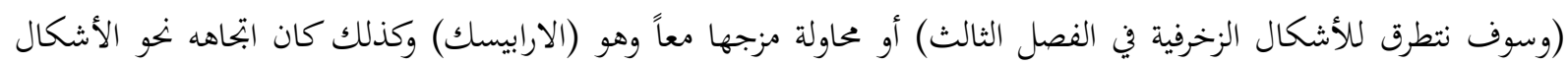

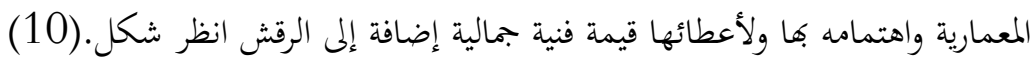

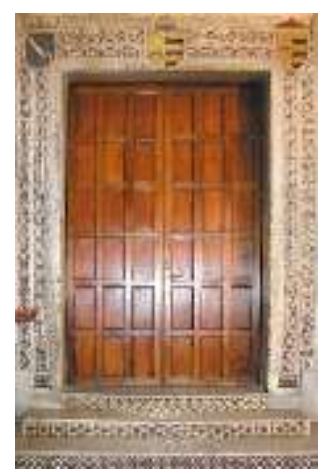

شكل (10) 

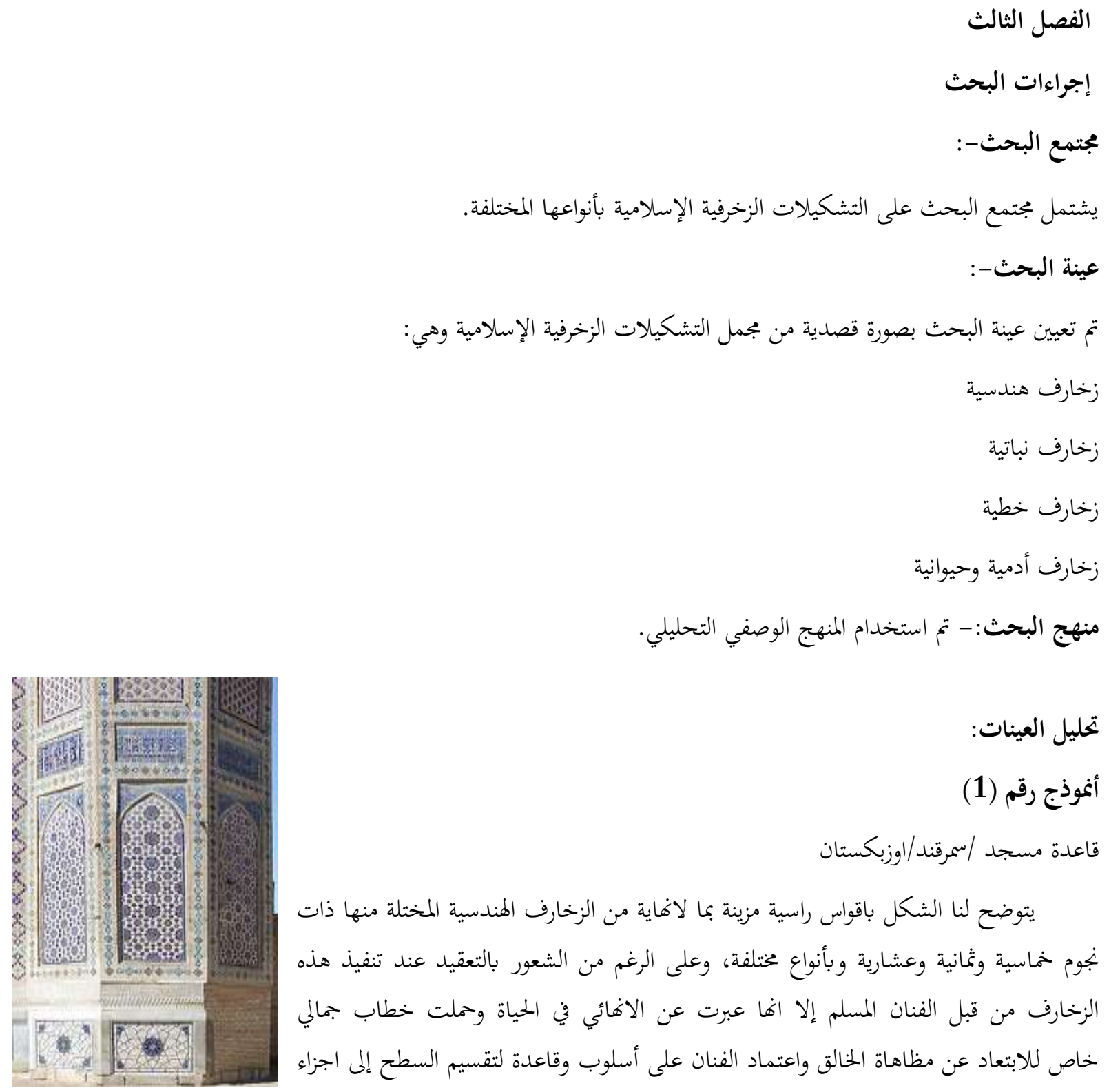

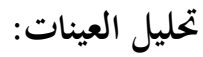

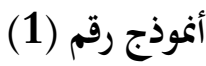

قاعدة مسجد /سمرقند/اوزبكستان

يتوضح لنا الشكل باقواس راسية مزينة بما لاهاية من الزخارف الهندسية المختلة منها ذات

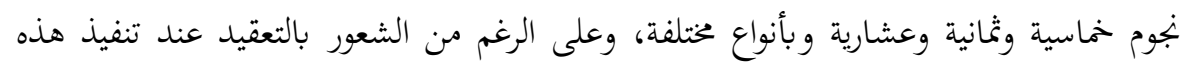

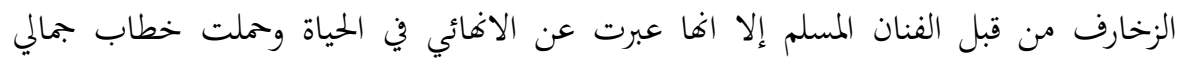
خاص للابتعاد عن مظاهاة الخالق واعتماد الفنان على أسلوب وقاعدة لتقسيم السطح إلى اجزاء متساوية لتنفيذ هذا النوع من الزخارف مما يعطي الانطباع لاهتمام الفنان المسلم بالشكل الهندسي نظريا وتطبيقيا فترتيب الأشكال الهندسية حملت نوع من الايقاع والتوازن والترتيب.

ان ابتحاه الفنان المسلم نحو الزخرفة هو محاولة نحو الاختزال واللاتشخيص فهو دائماً يبحث عن الروحي والقيم الظاهرة في

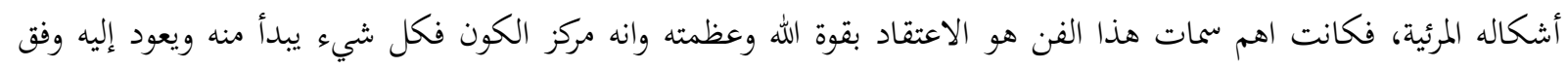

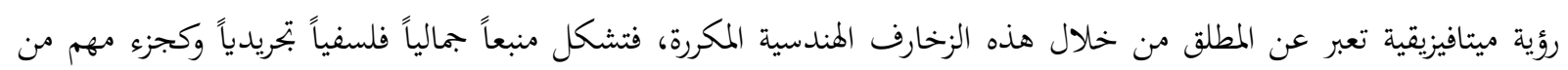

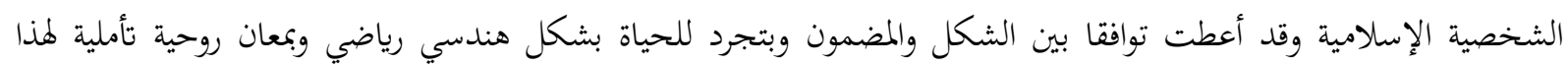

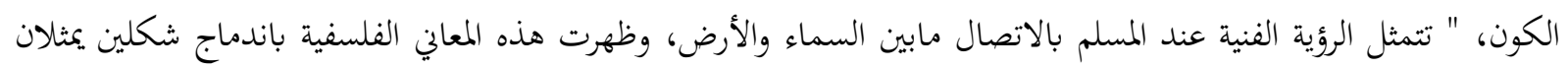

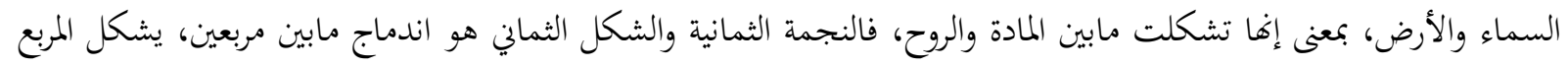

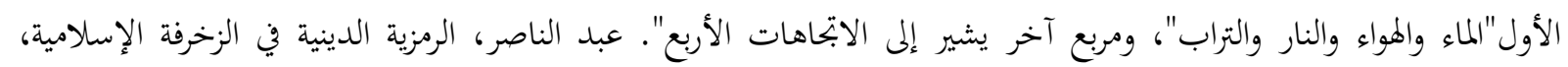

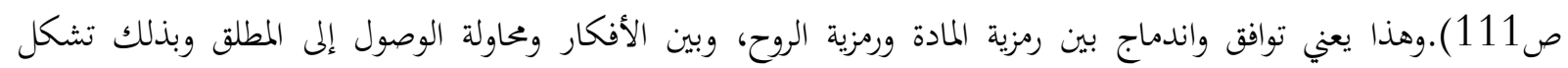
الوحدات الزخرفية حركة متتابعة فليس هناك بداية أو غهاية تمتعت بالديناميكية. 


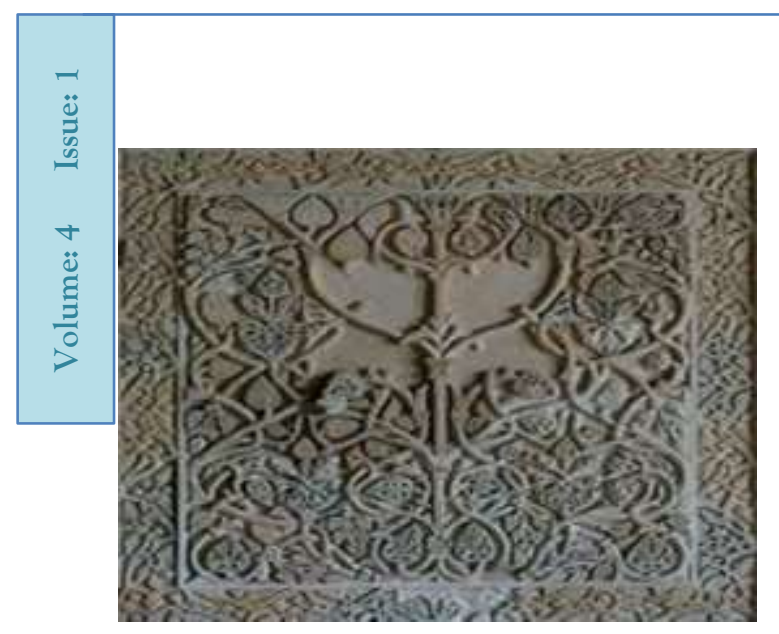

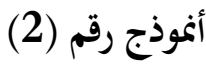

زخارف نباتية-سامراء

العنصر النباتي في الزخارف الإسلامية تأثر كثيرًا بانصراف المسلمين إلى

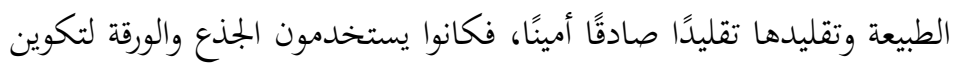
زخارف تمتاز بما فيها من تكرار وتقابل وتناظر، تدل على سيادة مبدأ التجريد والرمز في الفنون الإسلامية وأكثر الزخارف النباتية انتشارا في الفنون الإسلامية وناية

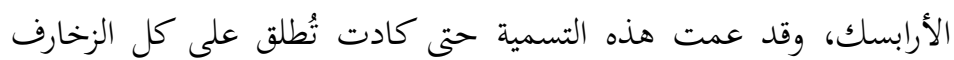

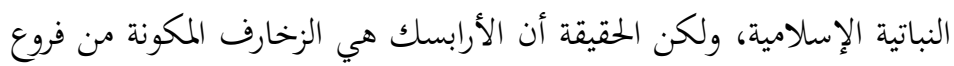

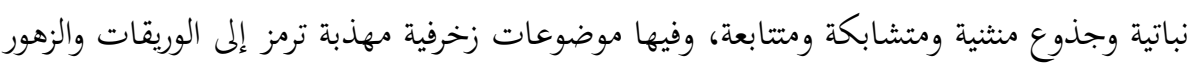
الحيز المجرد الفني الجمالي يتحول إلى بنية متجزئة ومشبعة بالضوء وتكوين مناخات ضوئية روحية تتنقل بين الساكن والمتحرك والفنان المسلم يحاول خلق مستويات على سطح الخامة وأي تغير في الضوء الساقط يعطي نوع من التغير في الوسيط الفني

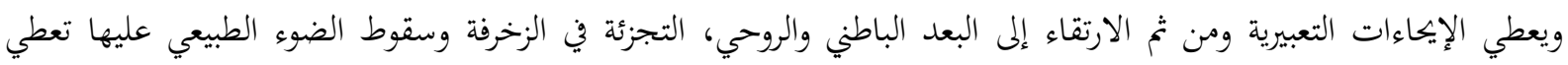

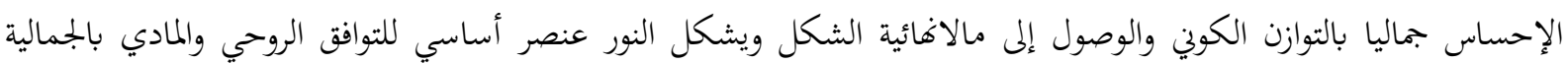

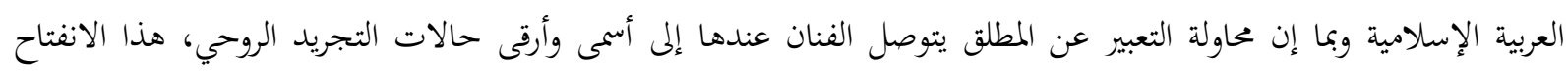

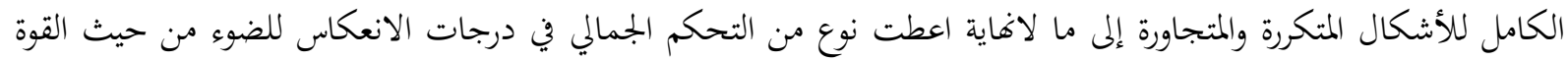

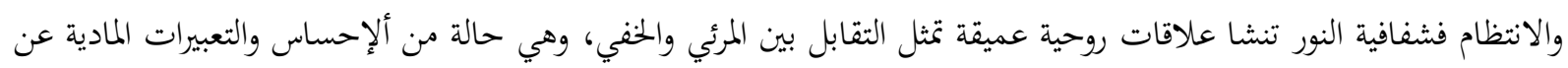

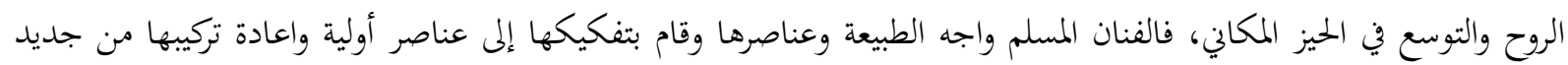

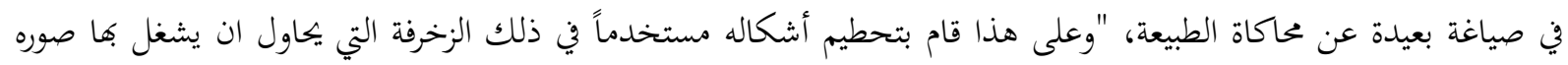

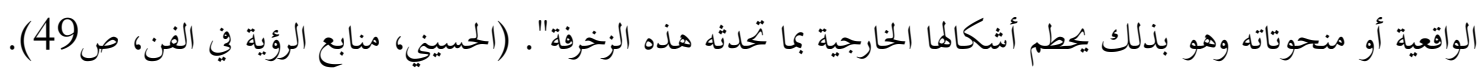

أنموذج رقم (3)

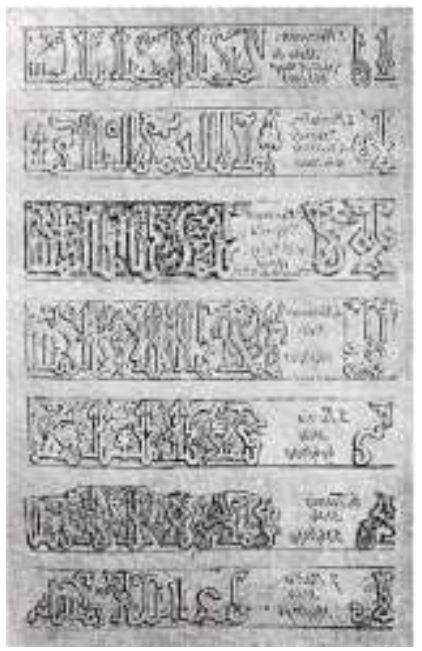

الخط الكوفي

يظهر لنا الشكل الزخري الكتابي حاملا خطاب فني جمالي منتظم، فالفنان المسلم

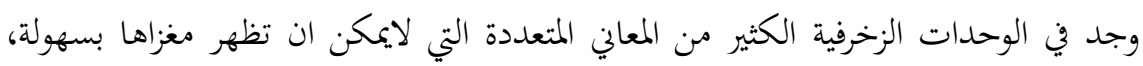

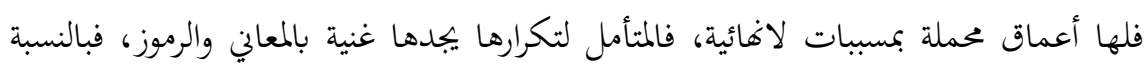

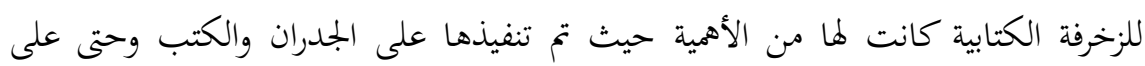
سطح الانيات الخزفية فالزخرفة الكتابية حملت مضمون واضح، والمضمون في منيك الزخرفة الإسلامية في الفن يرتكز إلى رموز تحتويه وتعبر عنه بشكل واضح للمتلقي.

ومن هذا المنطلق حمل الفنان المسلم الزخرفة الإسلامية رموزاً فنية تمتلك القدرة الذاتية

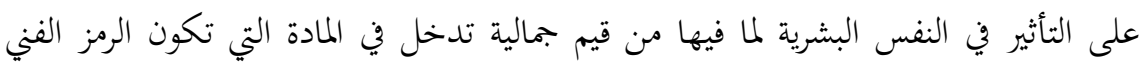
سواء على قطعه جلد أم على جدار، لهذا حاول المزخرف المسلم ان ينشئ من خلال أعماله الإبداعية صورة للعالم المطلق باستمرار وهي بهذا انعكاس للفكر الإسلامي، الزخرفة الكتابية الإسلامية تعد دعوة صريحة إلى التحرر من الماديات والتطلع إلى ما وراء

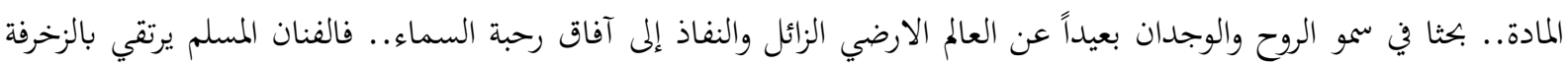


الإسلامية صعوداً إلى التشخيص والتجريد في ان واحد، فالتكرار هنا يحدد رياضياً في أوضاع وحجوم وهيئات متعاقبة في البعد الثالث في مستوى النظر وهو محدد بخط أفقي، فتستقر الحروف مع بعضها لتشكل نوع من التسلسل المتناسق حاملا نسقا زخرفيا متناغم مع السطح الذي تم تنفيذ هذا النوع من الزخرفة عليه.

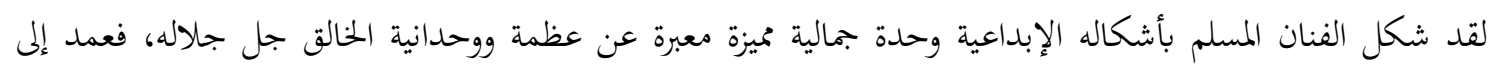
استخدام الزخرفة الكتابية بأسلوب فني جمالي وبصياغة ذات تناسق واضح فكان ذلك لكي يعبر عما في نفس الفنان المسلم من ونمان

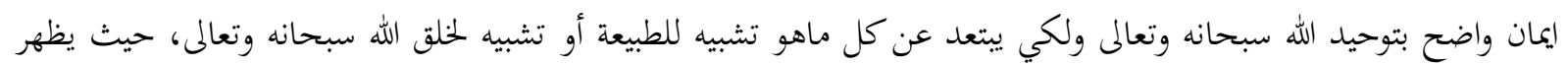

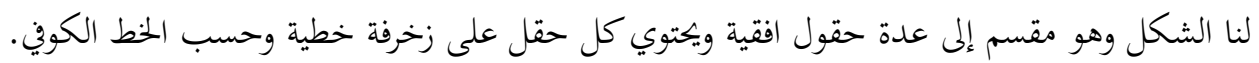

ابته الفنان المسلم بالحرف العربي من شكله البدائي إلى شكل فني زخرفي رائع ولم يعد له حد في التفنن والإبداع ولم يتخل

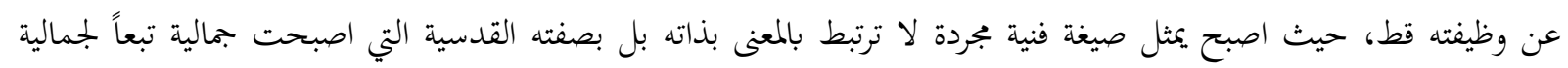

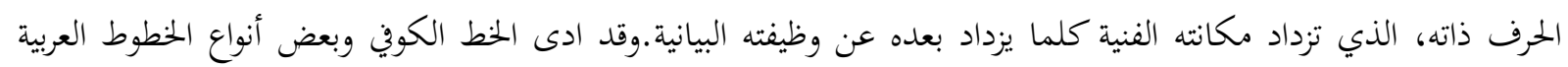

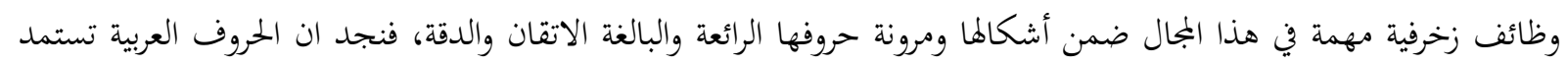

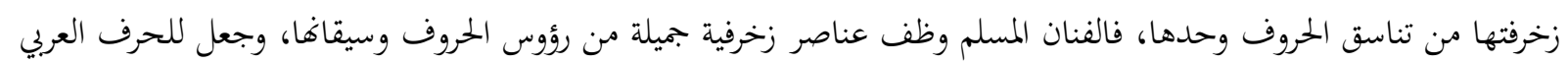

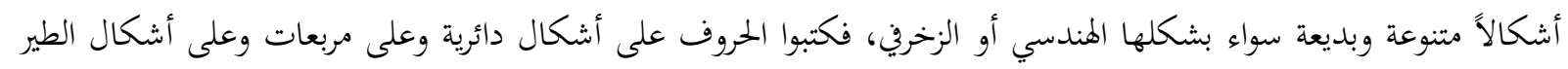

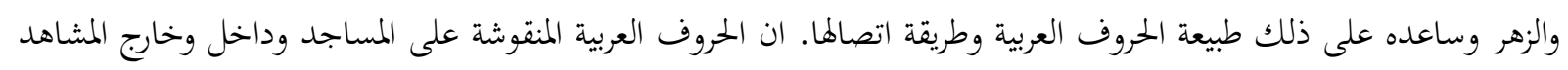

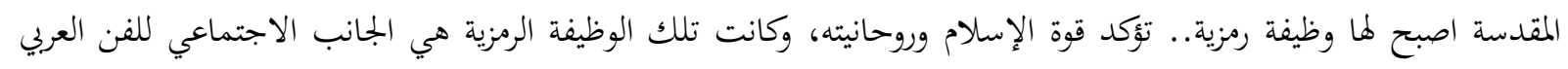

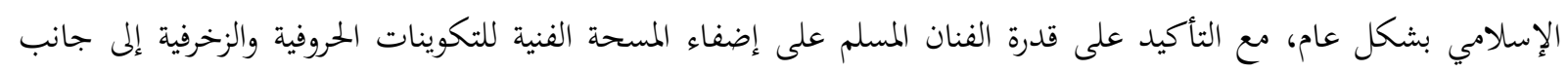
العطاء الروحي الذي يقدمه الإسلام.

\section{أنموذج رقم (4)}

\section{زخرفة أدمية وحيوانية}

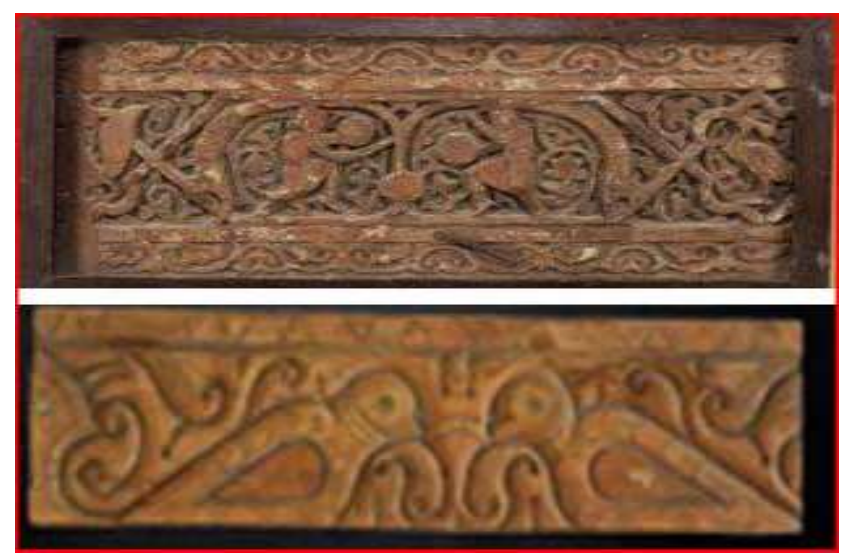

يظهر لنا الشكل الزخرفي الخشبي بأشكاله الأدمية في الجزء

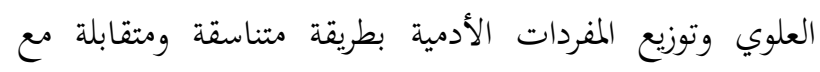
استخدام بعض الوحدات الزخرفية النبايتية وفي الحقل السفلي

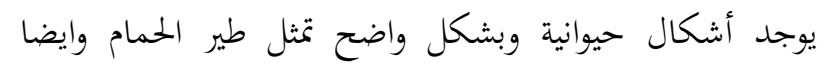
بوضعيه التقابل والتناظرمع وجود بعض الزخرفة عن طريق الخطوط وبنال

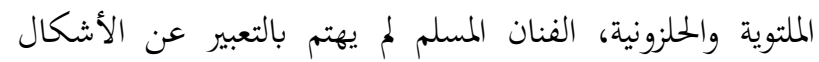

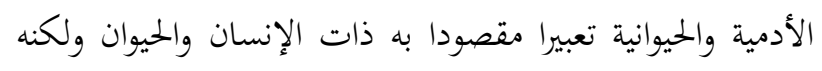
استخدم هذه العناصر كوحدات زخرفية بحتة لها قيمتها الفنية. وتبدو الأشكال قد بتاوزت المألوف لسعي الفنان إلى تحقيق وحدات زخرفية متنوعة. كانت الكائنات الحيّة وسيلةً تستخدم

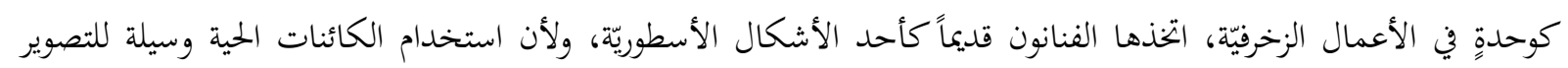

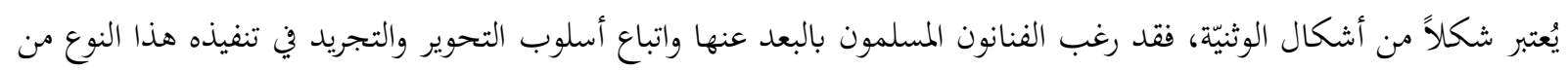
الزخرفة لأن تمثيل الشكل الحيواني والبشري بشكله الواقعي كان غير محبب عند الثند الإسلام. 
الفنان المسلم لم يكن يتجه كثيرا نحو الأشكال الأدمية والحيولنية لكن نجد في هذا الشكل الزخريف نوع من الجمالية الواضحة من خلال هذا التناظر اللامتناهي والمطلق، فالزخرفة بكل أنواعها تبتدا من نقطة ولاتنتهي محا يجعلها تتسم بالاستمرارية وهذا الشئ واضح للعيان عند المتلقي، ويظهر ايظا في هذا الشكل بساطة في تنفيذ الأشكال الأدمية حيث من الواضح لنا وجود اثنين من الرجال وهم بوضعية انحناء لواحدة من اقدامهم بينما تم الارتكاز على القدم الاخرى وكافم يقومون بتادية فعالية معينة من خلال هذا التقابل الواضح.ويبدو نفس الشيئ في تقبل الحمامات وكان هناك نوع من الخطاب فيما بينها صاغه هذا التقابل والتناظر والتماثل لتوصيل فكرة ذات رسالة جمالية لا متناهية وهو اتقان هذا النوع من الزخرفة بعيدة عن بتسيم الطبيعة الحية أو تصويرها محا حملت صياغة زخرفية أمتازت به الفنون الإسلامية، وبذلك لم تكن الكائنات الحية غاية وتعبيرا مقصود به ذات الإنسان والحيوان بل كانت وسيلة حتى يمكن استخدامها كوحدة زخرفية لما قيمة جمالية فنية فإضافة إلى الأشكال المختزلة الأدمية والحيوانية نفذ الفنان بعض الأشكال الاسطورية والمركبة لاها اتفقت في تركيبها في الابتعاد عن الحقيقة ومطابقة لصيغة التجريد التي اعتمدها الفنان ضمن المجال الزخرفي.

الفنان المسلم اتخذ من الجدران ايضا السطوح التي وذلك من مبدا كراهية الفراغ ولتغطية هذه السطوح والمساحات والاهتمام بمبدا التكرار ليحمل لنا الشكل خطاب جمالي نتيجة لصياغات جاءت متكررة ومتقابلة. 


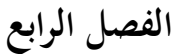

النتائج

1-الخطاب الجمالي يقوم على فلسفة الفنان المسلم من حيث الاعتقاد بلا غاية الوجود، فلمسلم يرى الله هو مركز الكون وكل شيء يبدء منه ليعود أليه . 2-الابتعاد عن تثثيل الطبيعة و تقليدها.

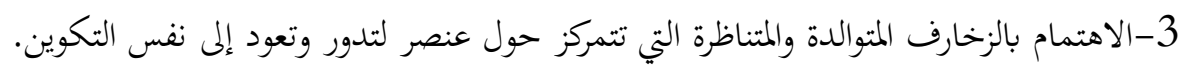

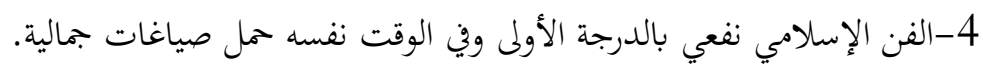

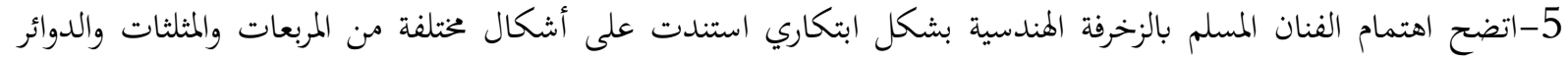
المتماسة والأشكال المتقاطعة بصيغة جمالية خالصة. 6-العناصر النباتية مصدرها فروع النبات واوراقه وازهاره ولكن بأسلوب معور.

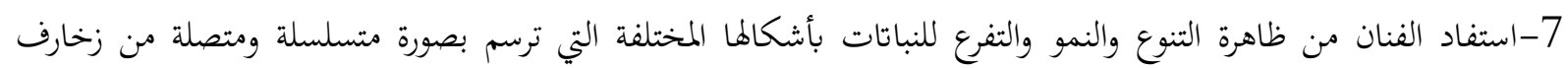
مستمرة ومتفرعة. 8- استخدم الفنان المسلم الخط العربي في الزخرفة والتزيين وفي بعض الاحيان أدخلوا عناصر نباتية في انتهاء الحرف.

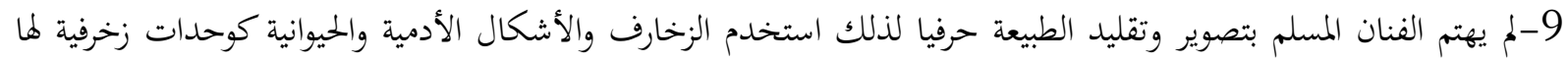
قيمتها الجمالية. 10-اشتهر الفن والتراث الإسلامي إضافة إلى الزخارف بفن الكتابة والتصوير وفن العمارة وفن الحزف وغيرها من الفنون التي جملت الطابع الجمالي. ضرورة الاهتمام باعادة تاهيل وترميم التراث الإسلامي للحفاظ عليه. - يجب توثيق الأشكال التراثية وخصوصا الزخارف وذلك نتيجة العثور على العدد القليل من المصورات الخاصة بالبحث. - استمرا ر الباحثين وطلبة العلم في دراسة الزخارف خصوصا وبأنواعها لما لها أهمية كبيرة لتعبيرها عن المطلق والماتلامتناهي. 


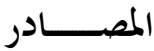

ابو ريان، محمد علي، فلسفه الجمال ونشأة الفنون الجميلة، دار الجامعات المصرية، ط5، الاسكندرية، 1977.

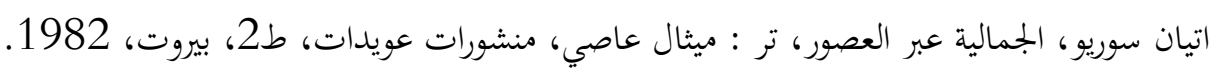

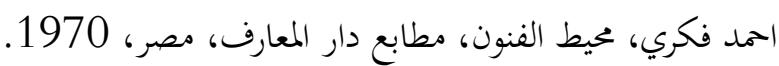

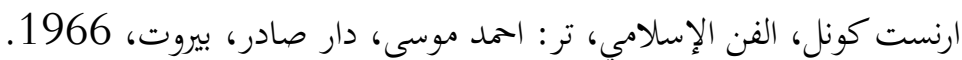

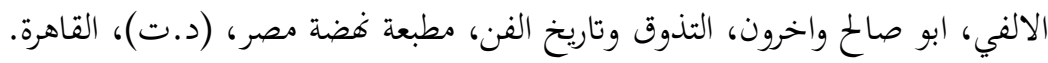
الاندلسي، ابو محمد علي بن احمد بن سعيد بن حزم، طوق الحمامة، بيروت، مؤسسة ناصر للطباعة، 1975.

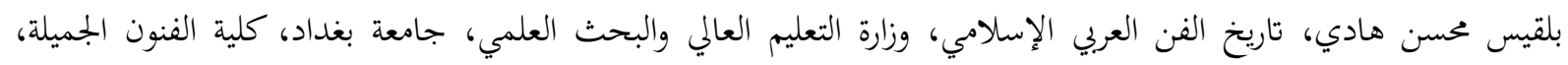
1990

التوحيدي، ابو حيان، الامتاع والمؤانسة، ج3، تحقيق:احمد امين واحمد الزين، القاهرة، مطبعة لجنة التاليف والترجمة والنشر، .1934

جميل صليبا: المعجم الفلسفي، ج1، منشورات ذوي القرب، إيران، ط1، 1385 هـ، . 1385

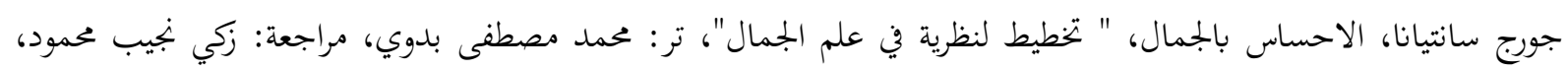

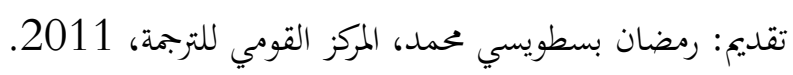

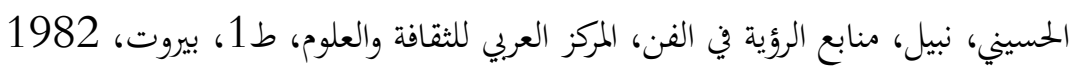
راجع المصدر، عبد السادة صاحب الخزاعي، الرسم التجريدي بين النظرة الإسلامية والرؤية المعاصرة، اطروحة دكتوراه (غير بروبات منشورة)، جامعة بغداد، كلية الفنون الجميلة، 1997.

الراوي، نوري، تأملات في الفن الإسلامي، بجلة الرواق، دائرة الفنون التشكيلية، وزارة الثقافة والاعلام، دار الحرية للطباعة.

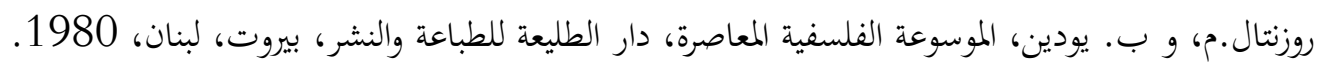

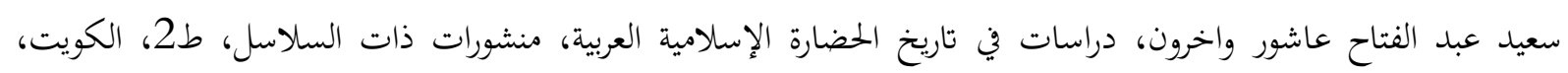
.1986

شوكت توفيق الالوسي، جماليات الأشكال المعمارية الإسلامية وانعكاسها في الرسم العراقي المعاصر، اطروحة دكتوراه (غير

$$
\text { منشورة)، جامعة بغداد، كلية الفنون الجميلة، } 2000 .
$$

العبيدي، جبار محمود، القيمه والمعيار الجمالي في التشكيل المعاصر، دار ضفاف للطباعة والنشروالتوزيع، ط1، العراق، 2013.

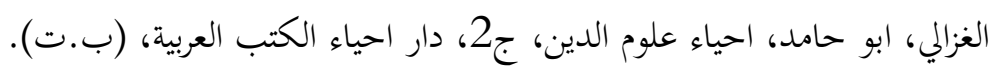

قتيبة صلاح عبد الله رمضان، خصائص التجريد في الخزف المعاصر في العراق، رسالة ماجستير (غير منشورة)، جامعة بغداد، كلية

$$
\text { الفنون الجميلة، } 2000 .
$$

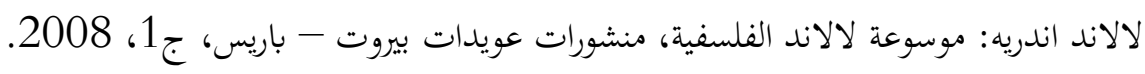

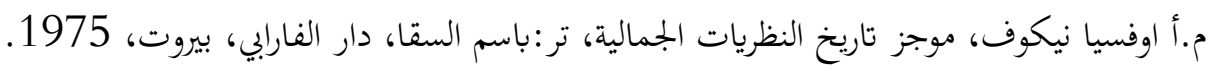

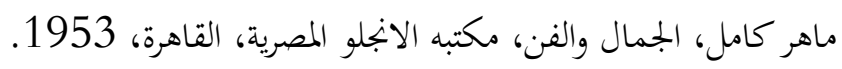

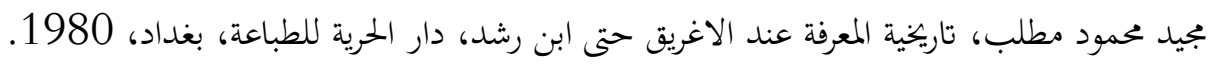

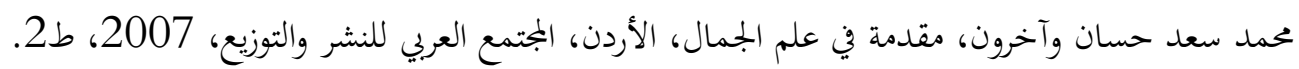

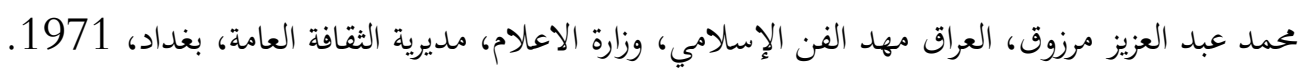

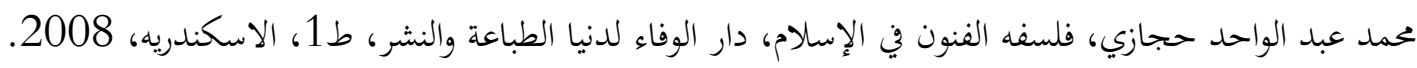


نجم عبد حيدر، علم الجمال آفاقه وتطوره، جامعة بغداد، كلية الفنون الجميلة، 2001.

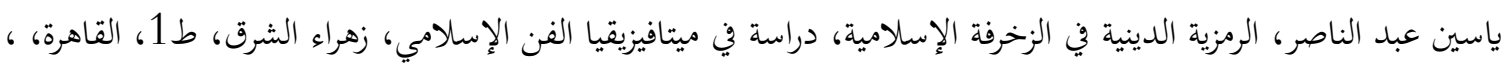
2006 